\title{
斑岩型铜矿床高-中温蚀变过程实验研究及其 地质意义
}

\author{
李建平 ${ }^{1,2}$, 陈华勇 ${ }^{1 *}$, 苏龙 ${ }^{3 \dagger}$, 肖兵 ${ }^{1}$ ，王云峰 ${ }^{1,2}$
}

1. 中国科学院矿物学与成矿学重点实验室/广东省矿物物理与材料研究开发重点实验室, 中国科学院广州地球化学研究所, 广州 510640 ;

2. 中国科学院大学, 北京 100049 ;

3. 中国科学院油气资源研究重点实验室/甘肃省油气资源研究重点实验室, 兰州 730000

* 通讯作者, E-mail: huayongchen@gig.ac.cn

†通讯作者, E-mail: longsu@1zb.ac.cn

收稿日期：2018-04-17; 收修改稿日期：2018-10-08; 接受日期：2018-10-30; 网络版发表日期：2018-12-28

国家自然科学基金-新疆联合重点项目(批准号: U1603244)、中国科学院战略性先导科技专项项目(编号: XDB1803206)和广东省科技计划项 目(编号: 2017B030314175)资助

摘要 作为金属 $\mathrm{Cu}$ 最重要来源的斑岩铜矿一般发育有典型的蚀变和矿化分带, 该分带模式在空间上常呈同心圈 层结构. 对不同蚀变带元素变化规律和迁移机制进行深入研究，将有利于增进对整个斑岩体系演化过程的认识. 本研究采用流动体系水-岩反应装置来模拟斑岩铜矿形成过程中含矿热液与围岩的相互作用, 研究元素迁移机制 和蚀变分带形成的控制因素. 实验结果显示与较低温度相比, $450^{\circ} \mathrm{C}$ 实验产物中元素含量变化更加显著, 这表明温 度可能是影响水-岩体系内元素再分配的重要因素。温度是造成围岩钾硅酸盐化蚀变和Ca淋滤、活化的关键因 素, 而且高温下发生同等钠化蚀变需要更高的 $\mathrm{Na}^{+}$浓度. 温度也是控制体系中 $\mathrm{Ti} 、 \mathrm{Sr} 、 \mathrm{~Pb}$ 置换进入硅酸盐矿物的 重要因素。从实验产物推断, 在斑岩成矿系统中, 中-基性火山围岩由中心向外围 $\mathrm{K} 、 \mathrm{Ti}$ 含量应呈降低趋势, 而 $\mathrm{Ca} 、 \mathrm{Zn}$ 和 $\mathrm{Mn}$ 含量增加, $\mathrm{Na}$ 和 $\mathrm{Si}$ 在靠近高温蚀变带外围可能存在含量峰值或过渡区. 本研究为斑岩铜矿系统钾化 带的产生、钠化普遍缺失、硬石膏共生等重要地质现象的形成机理提供了实验和理论证据.

关键词斑岩铜矿, 水-岩作用, 流动体系, 元素迁移机制

\section{1 引言}

斑岩铜矿系统作为 $\mathrm{Cu} 、 \mathrm{Mo} 、 \mathrm{Au}$ 等金属的重要来 源，当前为全球提供了约 $75 \%$ 的 $\mathrm{Cu} 、 50 \%$ 的 Mo、 $20 \%$ 的 $\mathrm{Au}$ 和绝大部分 $\mathrm{Re}$, 以及少量其他金属, 如 $\mathrm{Ag} 、 \mathrm{~Pb}$ 、 Zn等(Sillitoe, 2010; Cooke等, 2014b). 绝大部分斑岩型
矿床分布于汇聚型板块边缘之上的俯冲带，其分布与 高氧逸度的埃达克质岩浆作用有明显的亲缘性, 并与 构造挤压环境密切相关(Sillitoe, 1972; Kerrich，2000; Cooke等, 2005; 陈华勇和肖兵, 2014). 在汇聚板块边 缘, 俯冲板片脱水形成的流体交代上覆地幔楔, 使其部 分熔融形成高氧逸度富水岩浆(Ringwood，1977; Ri- 
chards和Kerrich, 2007; Richards，2011; 孙卫东等, 2010), 之后经历MASH过程, 侵入地壳上部形成浅部 岩浆房, 内部岩浆沿周围断裂系统上侵并且经过压力 释放发生流体出溶, 形成富含金属元素的成矿热液 (Hildreth和Moorbath, 1988; Harris等, 1990; Landtwing 等, 2005), 热液中金属元素在有限空间内沉降导致斑 岩型矿化. 含矿热液迁移过程中与围岩发生相互作用 形成一系列的蚀变和矿化分带. 典型斑岩型矿床核部 发育有钾化带, 外围被近乎同期形成的青磐岩化带所 包裹, 稍晚期形成绢英岩化带、泥化带和高级泥化带 叠加在早期蚀变之上(Lowell和Guilbert, 1970; Sillitoe, 2010). 钾化蚀变是斑岩铜矿最早的蚀变类型, 与高温 岩浆热液直接相关, 其主要分布于致矿侵入体顶部和 与侵入体接触的围岩之中, 早期的岩浆-热液转化阶段 也是高温热液从硅酸盐岩浆中萃取成矿金属和含硫物 质的重要过程. 全球许多大型斑岩型铜矿的成矿主体 均位于钾化带内, 该带内主要蚀变矿物组合包括钾长 石、黑云母、石英、硬石膏, 磁铁矿及一些铜铁硫化 物组合(Sillitoe, 1973; Cooke等, 2014b). 因此, 研究斑 岩铜矿不同温度蚀变带, 尤其是高中温蚀变带的形成 机制、控制因素及元素行为, 对揭示成矿热液演化过 程和矿化机制具有重要意义. 传统的研究方法是通过 地质观察, 显微岩相学及流体包裹体测试, 结合同位 素组成和相应的蚀变矿物组合, 从而确定成矿流体的 一些物理化学性质, 并推测相应的蚀变和矿化条件, 如流体的来源、温度、 $f \mathrm{O}_{2} 、 \mathrm{pH}$ 、盐度和主要组成等. 以上方法均是通过研究结果间接推断出成矿流体的演 化, 但实际上斑岩铜矿的形成往往经历了多期次的岩 浆热液叠加作用, 产生了大量的次生流体包裹体和复 杂的蚀变矿物组合特征. 这些因素会对成矿流体演 化、蚀变机制和控矿因素研究的准确性造成不容忽视 的影响.

随着实验和分析测试水平的提高, 选用适当的地 球化学模型进行实验研究, 已成为研究地质过程的一 种可靠手段. 化学平衡理论为理解封闭体系内水-岩作 用过程提供了理论基础, 应用该理论能解决封闭体系 内平衡热力学及部分反应动力学问题(Helgeson, 1969; Ré等, 2014). 前人对封闭体系内矿物与热液的反应进 行了大量的实验研究, 如 $300 \sim 400^{\circ} \mathrm{C}$ 和 $200 \mathrm{MPa}$ 温压条 件下含 $\mathrm{K}^{+} 、 \mathrm{Na}^{+} 、 \mathrm{Ca}^{2+} 、 \mathrm{Cl}^{-}$和长石、云母、黏土矿物 的封闭体系内发生的碱交代、热液蚀变和细碧岩化作
用(Winkler和Platen, 1961; Orville, 1962), 初步确定了 体系内发生的主要化学反应和矿物相变条件. 还有在 $\mathrm{Na}_{2} \mathrm{O}-\mathrm{K}_{2} \mathrm{O}-\mathrm{Al}_{2} \mathrm{O}_{3}-\mathrm{SiO}_{2}-\mathrm{H}_{2} \mathrm{O}$ 体系内确定了热液蚀变、 $\mathrm{H}^{+}$交代机制和影响钾长石、钠长石发生相变的条件 (Hemley, 1959; Hemley和Jones, 1964; Hemley等, 1980; Sverjensky等, 1991; Haselton等, 1995), 以及在 $400 \sim 750^{\circ} \mathrm{C}$ 和 $40 \sim 80 \mathrm{MPa}$ 条件下钾长石-云母-红柱石-石 英-卤水封闭体系中, 确定了钾长石的稳定区间和发生 相变的边界条件(Frank等, 1998; Frank和Vaccaro, 2012).

以上实验均是在简单封闭体系内完成, 主要研究 体系内化学反应和相变过程的控制因素, 但没有考虑 体系内流体组成在空间上的梯度效应. 而矿床的蚀变 和矿化是多重因素耦合的复杂过程, 含矿流体并非在 封闭空间内参与反应, 而是沿一定梯度方向进行迁移 并伴随着体系内物质的交换, 成矿流体与围岩相互作 用仅使局部范围达到平衡或亚平衡状态, 从而最终形 成一系列不同特征的蚀变和矿化分带(Barnes, 1997). 而流动体系内的水-岩反应实验研究采用一组流体连 续流经柱状岩石样品, 流体在可渗透岩石内以渗滤和 扩散方式进行迁移并和岩石逐渐反应, 产生一系列具 有空间维度特征的蚀变面(Reed, 1997). 因此, 在流动 体系内进行的水-岩反应实验研究更加接近真实的地 质过程. 流动体系模型最早是用于研究水-岩交代蚀变 过程(Korzhinskii，1959，1970)及其造成的同位素组成 分带现象(Bickle和Baker，1990; Ferry和Dipple，1991， 1992). 其他应用如利用流动水-岩体系模拟锡的萃取 实验表明, 由于流动体系内矿物发生反复溶解和沉淀 过程, 使得产物中锡品位比封闭体系产物高一个数量 级(Heinrich, 1990), 其结果更加符合实际情况. 流动 水-岩反应体系的应用还包括对沉积岩赋存铜矿成矿 机制(Merino等, 1986)、岩浆热液交代型矿床的形成 过程(Holyland, 1987)和地下水淋滤导致斑岩型铜矿的 表生富集过程(Ague和Brimhall, 1989)进行研究, 以及 低温条件下玄武岩与富 $\mathrm{CO}_{2}$ 卤水反应过程的实验研究 等(Rogers等, 2006; Luhmann等, 2017). 本实验参照典 型斑岩铜矿成矿前高温(钾化)蚀变带内单个流体包裹 体LA-ICP-MS分析结果来配置成矿流体(Halter等, 2002; Rusk等, 2004, 2008; Heinrich, 2005; Landtwing 等, 2005, 2010), 在流动水-岩反应装置内与斑岩矿区 常见的玄武安山质火山围岩反应, 反演斑岩铜矿形成 
过程中成矿热液与围岩的交代作用，来研究斑岩铜矿 蚀变特征及元素迁移机制并探讨其地质指示意义.

\section{2 样品和实验方法}

\section{1 岩石样品}

本次实验的岩石样品采自新疆东天山土屋-延东 斑岩铜矿区外围企我山群火山岩地层(土屋-延东斑岩 铜矿的主要围岩), 为玄武安山质火山岩, 属于斑岩铜 矿典型的火山围岩. 岩石手标本呈灰黑色, 斑状结构, 块状构造，斑晶以斜长石(约占 $65 \mathrm{vol} . \%)$ 、单斜辉石 (10vol.\%)、斜方辉石(5vol.\%)为主，基质(20vol.\%)呈 隐晶质和玻璃质(图 $1 \mathrm{a}$ 和 $1 \mathrm{~b}$ ). 部分斜长石局部发生弱 的绢云母和黏土化，且有少量绿帘石分布，进行实验 所挑选的样品尽量避开蚀变较强部位和后期次生细 脉, 选取相对较新鲜的部分. 将挑选的岩石样品除去表 层后在无污染环境下破碎成粒径约为 $1 \mathrm{~cm}$ 的颗粒，将 破碎的岩石颗粒在 $0.1 \mathrm{~mol} \mathrm{~L}^{-1}$ 的稀盐酸中浸泡 $24 \mathrm{~h}$ 以除 去样品中杂质和次生组分, 之后用去离子水反复冲洗 至中性并烘干. 选取 $50 \mathrm{~g}$ 处理好的岩石样品颗粒，粉碎 至200目以下进行全岩组分分析, 其余样品颗粒破碎至 40 60目混合均匀后进行物理实验, 将样品颗粒破碎是 保证初始样品的均一性和尽可能提高实验过程中水岩反应速率.

\section{2 初始流体}

由于新疆土屋-延东铜矿属于古生代斑岩铜矿, 受 后期热液影响明显，成矿流体具有多期特征(Xiao等, 2015; 王云峰等，2016)，且缺乏精确的单个包裹体成 分研究工作。本次实验初始流体盐度和实验温度范围 参考典型斑岩铜矿流体包裹体研究结果(Roedder, 1971; Nash, 1976; Heinrich, 2005), 如Nash(1976)对美 国37个斑岩铜矿床进行了流体包裹体岩相学研究, 并 根据不同矿床流体包裹体的物理化学特性及在矿床中 的空间分布特征，将流体包裹体按盐度和均一温度主 要分为高温高盐度和中-低温低盐度两大类型，而 Heinrich(2005)也将斑岩铜矿体系中流体包裹体根据 均一温度和盐度划分为两大类型. 两者划分的两种流 体包裹体类型的温度和盐度范围总体较为接近，其中 一组包裹体盐度和温度范围为 $2 \sim 20 \mathrm{wt} . \%\left(\mathrm{NaCl}_{\mathrm{eq}}\right)$ 和 $200 \sim 450^{\circ} \mathrm{C}$; 另一组包裹体盐度和温度范围为 $27 \sim$

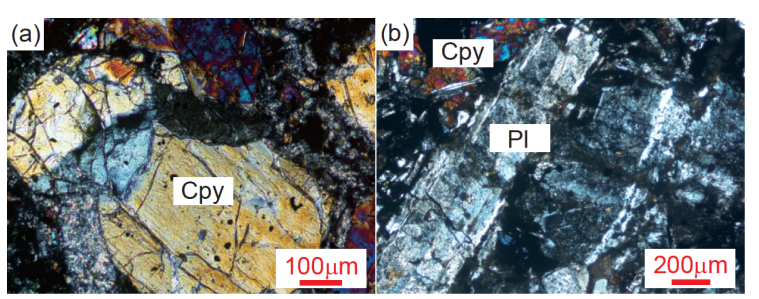

图 1 (网络版彩图)原始岩石样品显微镜下照片 岩石呈斑状结构, 斑晶主要为斜长石并含有少量单斜辉石. (a) 单斜 辉石; (b) 斜长石

$80 \mathrm{wt} . \%\left(\mathrm{NaCl}_{\mathrm{eq}}\right)$ 和 $250 \sim 750^{\circ} \mathrm{C}$, 实验设置的温度和实验 初始流体的总盐度均处在以上研究结果的范围之内.

实验初始流体中主要组分类型和含量根据全球典 型斑岩铜矿成矿前高温蚀变带内的单个流体包裹体 LA-ICP-MS分析结果进行配置, 本文主要参照了Butte 斑岩 $\mathrm{Cu}-\mathrm{Mo}$ 矿床内早期未矿化石英脉内流体包裹体组 成(Rusk等，2004，2008)，以及Bingham斑岩 Cu-Mo-Au 矿床矿化前早期石英脉内流体包裹体组成(Landtwing 等, 2005, 2010). 以上两类流体包裹体组成可以近似代 表岩浆出溶的原始成矿流体成分，均显示了以 $\mathrm{Na}^{+}$、 $\mathrm{K}^{+} 、 \mathrm{Cu}^{2+}$ 为主要阳离子的成矿流体组成, 此外 $\mathrm{Fe}^{2+}$ 、 $\mathrm{Ca}^{2+}$ 也是斑岩成矿流体较为重要的组成. 本次实验配 置的流体只关注了部分最为重要的元素和一些特征指 示性元素，所以实验流体只是对实际成矿热液的一种 近似模拟. 虽然实际成矿流体中也有较高含量的 $\mathrm{Ca}^{2+}$ 和 $\mathrm{Fe}^{2+}$, 但室温条件下在实验流体中添加大量的 $\mathrm{Ca}^{2+}$ 和 $\mathrm{Fe}^{2+}$ 存在较多技术问题. 首先 $\mathrm{CaSO}_{4}$ 在室温下溶解度 很低, 由于初始流体中含有较高浓度的 $\mathrm{SO}_{4}^{2-}$, 加入 $\mathrm{Ca}^{2+}$ 会导致形成大量的 $\mathrm{CaSO}_{4}$ 沉淀并造成初始溶液内硫含 量显著降低. 其次初始溶液中如果加入大量 $\mathrm{Fe}^{2+}$, 由于 实验周期较长，储存容器内溶液中的 $\mathrm{Fe}^{2+}$ 不稳定易发 生水解. 对Bingham矿床内液相流体包裹体LA-ICP$\mathrm{MS}$ 分析结果显示, $\mathrm{Mg}$ 是除 $\mathrm{Na} 、 \mathrm{~K} 、 \mathrm{Ca}$ 之外一种含量 相对较高的碱土金属, 因此在实验流体还中添加了 $\mathrm{Mg}^{2+}$. 前人研究结果显示 $\mathrm{Ti}^{4+} 、 \mathrm{Sr}^{2+} 、 \mathrm{~Pb}^{2+}$ 元素在斑岩 系统特定矿物内可作为指示元素，离矿体距离的不同 其含量具有很好的变化规律, 在确定热液中心过程中 具有很好的勘查指示作用(Cooke等，2014a，2017; Wilkinson等, 2015). $\mathrm{Ti}^{4+} 、 \mathrm{Sr}^{2+} 、 \mathrm{~Pb}^{2+}$ 虽在成矿流体中 含量较低，但是在本次实验流体中加入以上三种元素 作为指示元素，来揭示岩浆热液和火山围岩间这些特 
征元素的迁移倾向性，并根据围岩中其含量的变化趋 势提供初步的勘查指标. 因此, 实验配置流体内主要阳 离子包括 $\mathrm{Na}^{+} 、 \mathrm{~K}^{+} 、 \mathrm{Cu}^{2+} 、 \mathrm{Mg}^{2+}$ 及微量的 $\mathrm{Ti}^{4+} 、 \mathrm{Sr}^{2+}$ 、 $\mathrm{Pb}^{2+}$, 主要阴离子为 $\mathrm{Cl}^{-}$和 $\mathrm{SO}_{4}^{2-}$ 及微量 $\mathrm{NO}_{3}^{-}($表 1$)$. 其中 在初始流体中加入相等微量的 $\mathrm{Sr}\left(\mathrm{NO}_{3}\right)_{2}$ 和 $\mathrm{Pb}\left(\mathrm{NO}_{3}\right)_{2}$, 由于加入实验流体的 $\mathrm{Sr}^{2+}, \mathrm{Pb}^{2+}$ 随后会形成难溶电解 质，根据室温下对应的溶度积常数计算两者的浓度, 分别介于 $1.0 \times 10^{-6} \sim 1.88 \times 10^{-6} \mathrm{~mol} \mathrm{~L}^{-1}$ 和 $4.7 \times 10^{-8} \sim 9.4$ $\times 10^{-8} \mathrm{~mol} \mathrm{~L}^{-1}$ 范围内. 本次实验流体采用优级纯化学试 剂和去离子水配置，配置溶液前向去离子水中通 $\mathrm{N}_{2}$ 三 小时以排除其中空气.

\section{3 水-岩反应模拟装置及实验步骤}

水-岩反应实验研究的应用主要包括封闭静态体 系模拟和开放流动体系模拟, 封闭体系实验主要是进 行平衡热力学和反应动力学研究, 来确定水岩体系内 发生的主要化学反应和矿物相稳定存在的边界条件, 以及反应速率和机制问题(Brimhall，1977；Bird，1984; Hutcheon等, 1993), 但封闭体系实验不能指示物理化 学反应和产物组成在三维空间内沿某一梯度方向上的 变化特征. 此外, 封闭体系实验过程中如果设置过高的 水/岩比值也可能与实际的地质事实不相符，如模拟地 壳深部环境的水-岩反应, 在深部岩石孔隙率一般小于 10\%, 因此水-岩比值较小(Heinrich等, 1996). 而流动体 系内进行水-岩反应实验研究, 考虑了流体的流动方向 和流体组分在空间上的梯度效应。流体以渗滤和扩散 的方式在围岩中迁移并沿流向产生一系列的蚀变面, 通过对这些蚀变面进行岩相学和化学组成分析, 能更 好的揭示整个水-岩作用的演化过程以及蚀变产物在 空间上的变化特征(Carmichael，1987；Lasaga和Rye, 1993), 因此流动体系实验研究更加符合实际的地质 过程.

本次实验研究在中国科学院油气资源研究重点实 验室进行, 利用流动式高温高压水-岩作用模拟仪(图 2a)完成. 该装置属于半开放流动体系，主要由高温高 压反应系统、反应流体自动收集和充填系统、实验参 数自动检测及辅助系统三部分组成. 模拟仪主体包括: 高温高压反应釜(图2b)，加热仓、静岩压力控制系 统、流体压力控制系统和反应流体产物收集装置. 该 模拟仪加热温度范围为 $50 \sim 650^{\circ} \mathrm{C}$, 静岩压力范围为 $0 \sim 280 \mathrm{MPa}$, 流体压力范围为 $0 \sim 150 \mathrm{MPa}$. 实验温度、静 岩压力和流体压力的误差范围分别为 $\pm 1{ }^{\circ} \mathrm{C} 、 \pm 1 \mathrm{MPa}$ 和 $\pm 0.5 \mathrm{MPa}$. 实验岩石样品填充在反应釜样品仓内, 样品 仓内径 $2.5 \mathrm{~cm}$, 总长 $14 \mathrm{~cm}$, 样品仓最大容样量约 $150 \mathrm{~g}$, 充填一定量样品后仓内剩余空间用合金垫块补齐. 样 品仓两端与釜体密封配件相连接, 釜体一侧承受地层 压力并通过压力杆直接作用于仓内样品, 另一侧承受 主压力来均衡地层压力. 釜体两端的密封装置(图2c) 同时受到静岩压力和主压力的作用且在高温条件下铜 环发生塑性变形, 以达到密封整个反应釜体的目的. 釜 体两端与外部耐腐蚀合金导管相连，导管两侧分别连 接电磁阀和压力传感器来控制反应釜内流体的补充和 排放。

本次实验共设置的两个温度点, 分别是 450 和 $350^{\circ} \mathrm{C}$, 处于斑岩铜矿系统蚀变带形成温度范围内. 两 个温度点对应的静岩压力和流体压力分别为 $110 、 80$ $\mathrm{MPa}$ 和 45、35MPa. 根据地壳均衡模型并假设上地壳 平均密度为 $2.75 \mathrm{~g} \mathrm{~cm}^{-3}$ (Airy, 1855; 杜建国, 2010), 实 验静岩压力所对应的地层埋藏深度分别为 4 和 $3 \mathrm{~km}$, 而 斑岩铜矿形成于地壳浅部, 深度一般小于 $5 \mathrm{~km}$ (Sillitoe, 2010), 因此实验设置的静岩压力值符合典型斑岩铜矿 系统发育的深度范围. 其中静岩压力直接作用于岩石 样品，代表了上覆地层对蚀变深度范围内围岩的压实 作用. 反应釜内的实验流体主要充填在岩石样品裂隙 内，流体压力是以实验流体力为介质同时作用于反应 釜内围岩及裂隙内的流体本身，设置的流体压力大于 对应深度的静水压力值且基本符合典型斑岩铜矿成矿 流体压力范畴(Seedorff等, 2005; 张德会等, 2011). 因此

表 1 实验初始流体主要组成

\begin{tabular}{cccccccrr}
\hline $\begin{array}{c}\text { 实验 } \\
\text { 温度 }\end{array}$ & $\begin{array}{c}\text { 流体 } \\
\text { 总量 }(\mathrm{mL})\end{array}$ & $\begin{array}{c}\mathrm{Na}^{+} \\
\left(\mathrm{mol} \mathrm{L}^{-1}\right)\end{array}$ & $\begin{array}{c}\mathrm{K}^{+} \\
\left(\mathrm{mol} \mathrm{L}^{-1}\right)\end{array}$ & $\begin{array}{c}\mathrm{Cu}^{2+} \\
\left(\mathrm{mol} \mathrm{L}^{-1}\right)\end{array}$ & $\begin{array}{c}\mathrm{Mg}^{2+} \\
\left(\mathrm{mol} \mathrm{L}^{-1}\right)\end{array}$ & $\begin{array}{c}\mathrm{Ti}^{4+} \\
\left(\mathrm{mol} \mathrm{L}^{-1}\right)\end{array}$ & $\begin{array}{c}\mathrm{Cl}^{-} \\
\left(\mathrm{mol} \mathrm{L}^{-1}\right)\end{array}$ & $\begin{array}{c}\mathrm{SO}_{4}^{2-} \\
\left(\mathrm{mol} \mathrm{L}^{-1}\right)\end{array}$ \\
\hline $450^{\circ} \mathrm{C}$ & 500 & 1.24 & 0.48 & 0.06 & 0.11 & 0.003 & 1.72 & 0.17 \\
$350^{\circ} \mathrm{C}$ & 500 & 0.62 & 0.24 & 0.03 & 0.05 & 0.003 & 0.86 & 0.08 \\
\hline
\end{tabular}



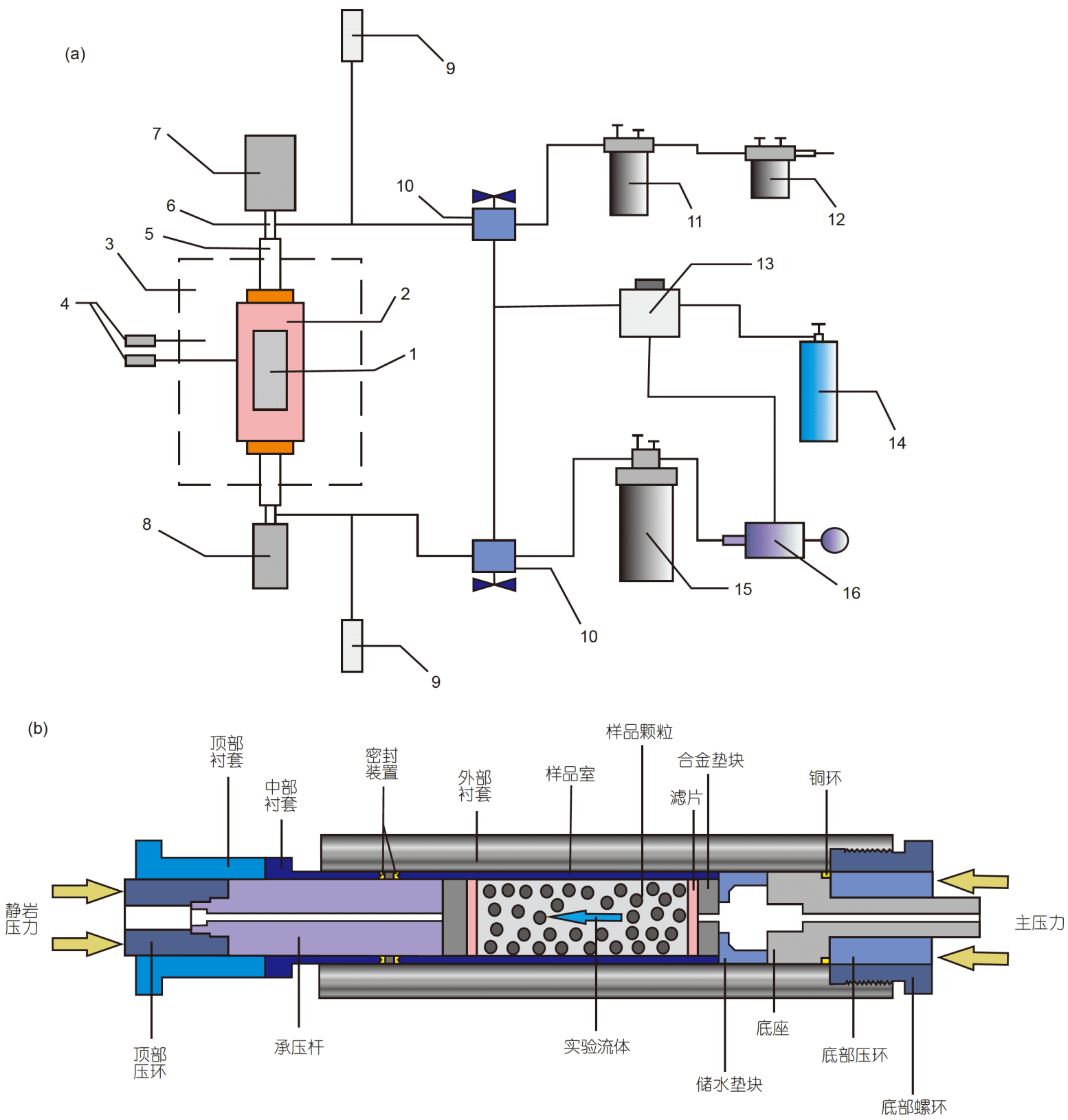

(c)

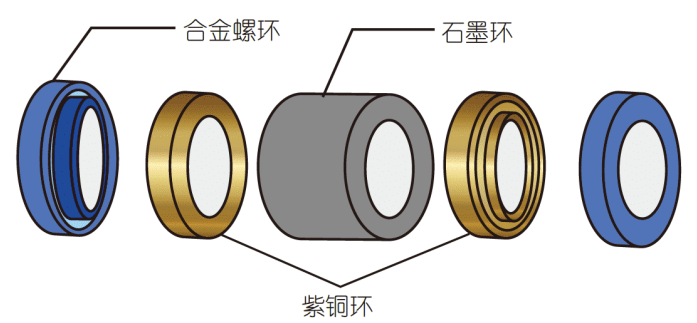

图 2 (网络版彩图)流动式高温高压水-岩反应模拟仪(a)、反应釜(b)、密封装置(c)示意图

1 , 代表样品仓; 2 , 反应釜; 3 , 加热炉; 4 , 温度传感器; 5 , 压杆护套 $; 6$, 压杆; 7 , 地层压力泵; 8 , 主压力泵; 9 , 压力传感器; 10 , 电磁阀; 11 , 气液分离 器(含冷阱); 12 , 气体收集器; 13 , 空气压缩机; 14 , 氮气; 15 实验流体; 16 , 高压㬌 
实验过程中围岩主要承受来自上方的静岩压力和周围 的流体压力，符合斑岩成矿系统内有裂隙和网脉发育 围岩的实际受力情况.

实验前在反应釜内充填好岩石样品，设置地层压 力和主压力来密封整个反应釜体，之后对整套装置进 行抽真空和检查气密性。实验开始后运行设置好的实 验程序并打开加热装置, 系统自动升温, 升温速率为 $10^{\circ} \mathrm{C} \mathrm{min}^{-1}$, 距离目标温度相差 $50^{\circ} \mathrm{C}$ 时升温速率降至 $2^{\circ} \mathrm{C} \mathrm{min}^{-1}$, 直到升至目标温度. 实验达到目标温度后, 在高压洜上设置流体压力值和压力阈值(阈值为 $\pm 0.5 \mathrm{MPa})$, 实验流体经导管恒流注入反应釜内, 当反应 釜内流体压力超过阈值范围时，出口侧电磁阀打开释 放微量流体使釜内压力降低到目标值，以保证实验过 程中釜内流体压力维持在目标值. 实验过程中流体流 动方式可视为间接性恒流模式，由反应釜排出的实验 流体流入含冷阱集液器内，每 $24 \mathrm{~h}$ 收集一次冷阱内实 验流体. 实验过程中目标温度、升温速率、静岩压 力、主压力、流体压力均可以通过自动控制系统进行 控制, 并由计算机自动监控和记录具体参数值. 待某一 温度点实验结束后，将反应釜迅速冷却至室温后取出 柱状岩石样品, 并标注流体流动方向以备进一步的分 析测试, 实验条件及具体参数如表 2 所示.

实验后的柱状岩芯样品(图3a和3c)沿流体流动方 向进行分段处理, 其中将 $450^{\circ} \mathrm{C}$ 产物分为三段(图3b), $350^{\circ} \mathrm{C}$ 产物分为两段(图3d). 将分段后的样品沿流向均 匀分为两部分, 将其中一半样品粉碎成粒状后用去离 子水冲洗干净、离心并烘干, 之后用玛瑙研钵磨制成 200 目以下岩石粉末进行全岩化学组成分析; 另一半 样品进行固化处理，切割后磨制成光薄片、探针片进 行显微岩相学观察及单矿物电子探针分析, 以上样品 处理过程均在无污染环境下进行.

\section{4 主-微量元素及电子探针分析}

全岩主量元素分析在澳实矿物实验室(广州)完成,
选用的仪器为ME-XRF26d型X射线荧光光谱仪 (XRF), 样品的含量由 36 种包含硅酸盐样品范围的参考标准物 质双变量拟合曲线确定，分析精度优于 $1 \%$. 微量元素 在中国科学院广州地球化学研究所同位素地球化学国 家重点实验室进行, 选用仪器为Thermo iCAP QC型质 谱仪, 其中稀土元素分析精度优于 $3 \%$, 其余微量元素 分析精度优于 $5 \%$, 具体实验流程和测试方法参考刘颖 等(1996).

电子探针分析在中国科学院广州地球化学研究所 矿物学与成矿学重点实验室JEOL JXA-8230型电子探 针仪上完成, 加速电压为 $15 \mathrm{kV}$, 测试电流为 $20 \mathrm{nA}$, 束斑 直径 $1 \mu \mathrm{m}$, 采用天然样品作为标样, 分析误差小于 $0.01 \%$.

\section{3 实验结果}

\section{1 岩石产物元素含量特征}

将实验产物主要氧化物组成去烧失量进行TAS投 图(图4), 结果显示 $350^{\circ} \mathrm{C}$ 实验产物岩性基本不变, $450^{\circ} \mathrm{C}$ 实验产物岩性由玄武粗安岩向响岩质碱玄岩过 渡, 岩性变化为热液蚀变导致. 全碱含量表明, 反应后 岩石中全碱含量增加且 $4500^{\circ} \mathrm{C}$ 实验产物增量明显大于 $350^{\circ} \mathrm{C}$ 实验产物. $\mathrm{K}_{2} \mathrm{O} / \mathrm{Na}_{2} \mathrm{O}$ 比值也有所变化, 原始样品 该值为 $1.24,450^{\circ} \mathrm{C}$ 实验产物该值介于 $1.43 \sim 1.72$, 明显 增高; 而 $350^{\circ} \mathrm{C}$ 实验产物该值介于 $1.21 \sim 1.22$, 呈微弱降 低. 靠近流体中心(流体入口处), $350^{\circ} \mathrm{C}$ 实验产物中 $\mathrm{SiO}_{2}$ 含量降低不明显, 而 $450^{\circ} \mathrm{C}$ 实验产物中 $\mathrm{SiO}_{2}$ 含量有明显 的降低.

微量元素蛛网图解(图5a)显示实验产物与原岩分 配模式较为接近, 均显示岛弧火山岩的地球化学特征, 富集大离子亲石元素 $\mathrm{Rb} 、 \mathrm{Ba} 、 \mathrm{~K} 、 \mathrm{Sr}$ ，亏损高场强元 素 $\mathrm{Th} 、 \mathrm{Nb} 、 \mathrm{Ta} 、 \mathrm{Zr} 、 \mathrm{Hf} 、 \mathrm{Ti}$. 实验产物稀土元素配分 图解均显示右倾型(图5b), 轻稀土轻微富集, 重稀土相 对亏损. $350^{\circ} \mathrm{C}$ 实验产物稀土元素含量接近原岩稀土含

表 2 实验温压条件及其他参数

\begin{tabular}{cccccccccc}
\hline 实验序号 & $\begin{array}{c}\text { 实验温度 } \\
\left({ }^{\circ} \mathrm{C}\right)\end{array}$ & $\begin{array}{c}\text { 静岩压力 } \\
(\mathrm{MPa})\end{array}$ & $\begin{array}{c}\text { 流体压力 } \\
(\mathrm{MPa})\end{array}$ & $\begin{array}{c}\text { 样品重量 } \\
(\mathrm{g})\end{array}$ & $\begin{array}{c}\text { 样品粒径 } \\
(\text { 目 })\end{array}$ & $\begin{array}{c}\text { 流体盐度 } \\
\mathrm{wt.} \%\left(\mathrm{NaCl}_{\mathrm{eq}}\right)\end{array}$ & $\begin{array}{c}\text { 反应时长 } \\
(\mathrm{h})\end{array}$ & $\begin{array}{c}\text { 流体收集频 } \\
\text { 率 }(\mathrm{h} / \text { 次 })\end{array}$ & $\begin{array}{c}\text { 单次收集量 } \\
(\mathrm{mL})\end{array}$ \\
\hline 01 & 450 & 110 & 45 & 70.0 & $40 \sim 60$ & 12.8 & 385 & 24 & 约28 \\
02 & 350 & 80 & 35 & 36.5 & $40 \sim 60$ & 6.9 & 410 & 24 & 约 15 \\
\hline
\end{tabular}




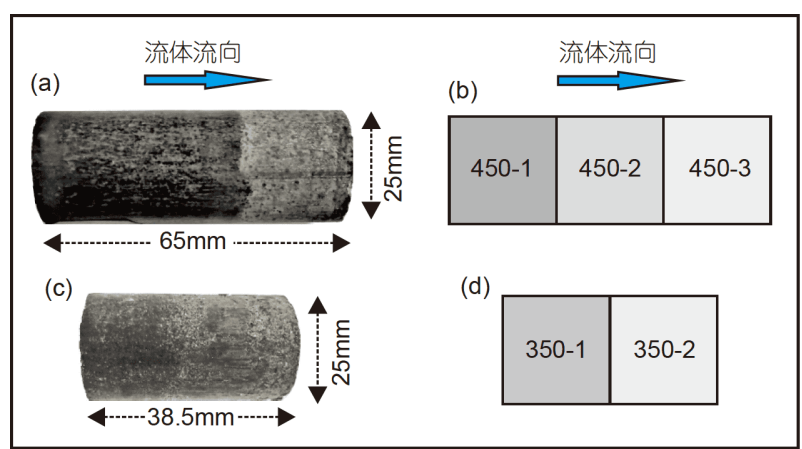

图 3 (网络版彩图)实验产物实物图((a), (c))和分段测试 ((b), (d))示意图

(a), (b) $450^{\circ} \mathrm{C}$ 产物; (c), (d) $350^{\circ} \mathrm{C}$ 产物

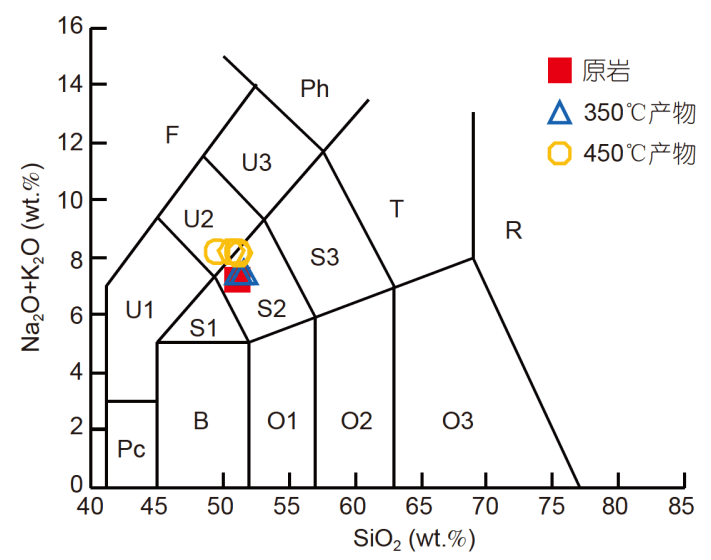

图 4 (网络版彩图)原始岩石样品及实验产物TAS图解

$\mathrm{B}$, 玄武岩; O1, 玄武安山岩; $\mathrm{O} 2$, 安山岩; $\mathrm{O} 3$, 英安岩; R, 流纹岩; $\mathrm{S} 1$, 粗面玄武岩; S2, 玄武粗安岩; S3, 粗面安山岩; $T$, 粗面岩和粗面英安 岩; Pc, 苦橄岩; U1, 碧玄岩和碱玄岩; U2, 响岩质碱玄岩; U3, 碱玄质 响岩; Ph, 响岩; F, 似长石岩

量, $450^{\circ} \mathrm{C}$ 实验产物稀土含量低于原岩和 $350^{\circ} \mathrm{C}$ 实验产 物. 原岩、 $350^{\circ} \mathrm{C}$ 和 $450^{\circ} \mathrm{C}$ 实验产物中总稀土含量依次 降低, $\sum \mathrm{REE}$ 平均值依次为 $136 、 132$ 和 $129 \mathrm{ppm}$ $\left(1 \mathrm{ppm}=1 \mathrm{mg} \mathrm{L}^{-1}\right)$. 原始岩石样品及实验产物化学组成 如表3所示.

\section{2 岩石产物元素空间分布特征}

实验产物主量元素分析结果显示，同一实验条件 下岩石样品与流体反应，岩石中不同元素相对含量具 有不同的变化趋势，显示出这些元素在水-岩体系中具 有不同的迁移倾向性. 而不同实验条件下, 同一元素含 量的变化范围也有明显的差异, 如 $450^{\circ} \mathrm{C}$ 实验产物中元 素含量变化幅度均大于 $350^{\circ} \mathrm{C}$ 实验产物，表明温度是
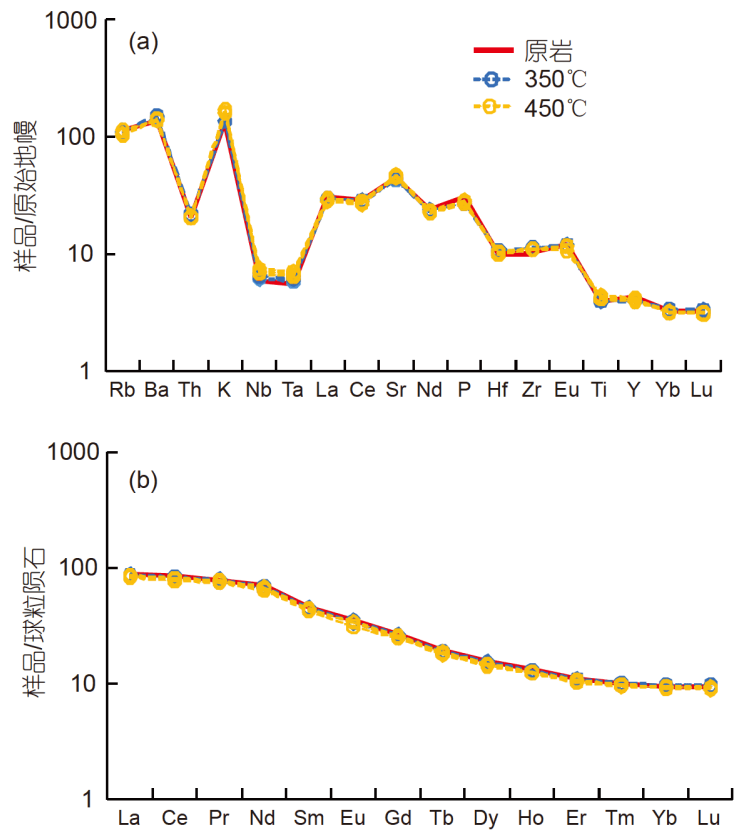

图 5 (网络版彩图)原始岩石样品及实验产物原始地幔标 准化蛛网图(a)和球粒陨石标准化稀土配分图(b)

微量元素标准化数据引自Sun和McDonough(1989)

水-岩体系中元素再分配的重要控制因素. 不同温度条 件下，实验产物中 $\mathrm{CaO}$ 和 $\mathrm{MgO}$ 均被淋滤(图6c和6d), 但 同一条件下这两种组分的空间分布不同，沿流体流向 $\mathrm{CaO}$ 淋滤程度逐渐变弱, $\mathrm{MgO}$ 淋滤程度逐渐变强. 与 之相反, 实验产物中 $\mathrm{K}_{2} \mathrm{O}$ 和 $\mathrm{TiO}_{2}$ 含量均增加(图6a和6f), 且 $450^{\circ} \mathrm{C}$ 实验产物增幅更为明显, 沿流体流向两者增加 的幅度逐渐减弱. $\mathrm{Na}_{2} \mathrm{O}$ 含量在 $350^{\circ} \mathrm{C}$ 实验产物中呈增 加趋势，在 $450^{\circ} \mathrm{C}$ 实验产物中沿流体流向先发生淋滤， 之后含量有所升高(图6b). 沿流体流向, 不同温度实验 产物中 $\mathrm{SiO}_{2}$ 均呈现先淋滤后增加的变化趋势(图6e), 两 者区别是远离流体中心(靠近流体出口), $350^{\circ} \mathrm{C}$ 实验产 物中 $\mathrm{SiO}_{2}$ 含量增加明显, 而 $450^{\circ} \mathrm{C}$ 实验产物中 $\mathrm{SiO}_{2}$ 含量 增加微弱. $450^{\circ} \mathrm{C}$ 实验产物中除 $\mathrm{MgO}$ 外, 其余主量元素 含量变化均在450-1处(靠近流体入口)达到峰值, $350^{\circ} \mathrm{C}$ 实验产物中该现象不明显.

实验产物微量元素分析结果显示，受流体作用影 响较为显著的微量元素有 $\mathrm{Cu} 、 \mathrm{Zn} 、 \mathrm{Mn} 、 \mathrm{Sr} 、 \mathrm{~Pb}$ 和 $\mathrm{S}$, 且不同温度条件下以上元素含量的变化具有较大差 异. $450^{\circ} \mathrm{C}$ 实验产物中, 以上元素含量的变化均强于 $350^{\circ} \mathrm{C}$ 实验产物，这表明高温条件下受流体作用，导致 岩石样品中这些元素发生强烈的亏损或富集. 实验产 
表 3 原始岩石样品及实验产物主量和微量元素组成

\begin{tabular}{|c|c|c|c|c|c|c|}
\hline 主量元素(wt.\%) & 原始样品 & $350-1$ & $350-2$ & $450-1$ & $450-2$ & $450-3$ \\
\hline $\mathrm{Al}_{2} \mathrm{O}_{3}$ & 17.34 & 17.51 & 17.70 & 17.20 & 17.48 & 17.52 \\
\hline $\mathrm{BaO}$ & 0.10 & 0.11 & 0.12 & 0.11 & 0.12 & 0.12 \\
\hline $\mathrm{CaO}$ & 6.25 & 5.66 & 5.71 & 5.00 & 5.54 & 5.68 \\
\hline $\mathrm{TFe}_{2} \mathrm{O}_{3}$ & 9.20 & 9.20 & 9.17 & 10.64 & 9.17 & 9.01 \\
\hline $\mathrm{K}_{2} \mathrm{O}$ & 3.92 & 3.96 & 4.01 & 5.05 & 4.77 & 4.67 \\
\hline $\mathrm{MgO}$ & 5.88 & 5.50 & 5.48 & 5.46 & 5.35 & 5.34 \\
\hline $\mathrm{MnO}$ & 0.14 & 0.13 & 0.13 & 0.10 & 0.11 & 0.11 \\
\hline $\mathrm{Na}_{2} \mathrm{O}$ & 3.15 & 3.28 & 3.30 & 2.93 & 3.27 & 3.26 \\
\hline $\mathrm{P}_{2} \mathrm{O}_{5}$ & 0.48 & 0.43 & 0.42 & 0.42 & 0.44 & 0.44 \\
\hline $\mathrm{SiO}_{2}$ & 49.85 & 49.37 & 50.28 & 48.26 & 49.95 & 49.87 \\
\hline $\mathrm{SO}_{3}$ & 0.02 & 0.11 & 0.05 & 0.95 & 0.39 & 0.16 \\
\hline $\mathrm{SrO}$ & 0.11 & 0.10 & 0.10 & 0.11 & 0.11 & 0.11 \\
\hline $\mathrm{TiO}_{2}$ & 1.14 & 1.15 & 1.15 & 1.27 & 1.21 & 1.20 \\
\hline LOI & 2.71 & 2.93 & 2.63 & 3.02 & 2.56 & 2.41 \\
\hline 总量 & 100.29 & 99.44 & 100.25 & 100.52 & 100.47 & 99.90 \\
\hline 微量元素(ppm) & 原始样品 & $350-1$ & $350-2$ & $450-1$ & $450-2$ & $450-3$ \\
\hline $\mathrm{Rb}$ & 72.70 & 69.08 & 71.06 & 72.20 & 67.24 & 65.75 \\
\hline $\mathrm{Ba}$ & 970.40 & 1017.40 & 1065.10 & 965.90 & 990.10 & 982.40 \\
\hline Th & 1.74 & 1.82 & 1.85 & 1.76 & 1.77 & 1.73 \\
\hline $\mathrm{Nb}$ & 4.14 & 4.38 & 4.61 & 4.44 & 4.68 & 4.93 \\
\hline $\mathrm{Ta}$ & 0.23 & 0.24 & 0.25 & 0.24 & 0.26 & 0.27 \\
\hline $\mathrm{Sr}$ & 940.50 & 903.70 & 930.90 & 967.50 & 949.60 & 991.20 \\
\hline $\mathrm{Hf}$ & 3.07 & 3.15 & 3.32 & 3.18 & 3.22 & 3.08 \\
\hline $\mathrm{Zr}$ & 114.60 & 124.50 & 126.60 & 124.60 & 122.50 & 121.80 \\
\hline $\mathrm{U}$ & 0.58 & 0.58 & 0.62 & 0.56 & 0.57 & 0.56 \\
\hline $\mathrm{Y}$ & 19.48 & 18.08 & 18.43 & 19.03 & 17.90 & 18.47 \\
\hline $\mathrm{Cu}$ & 70.72 & 368.40 & 180.20 & 1846.60 & 750.60 & 560.50 \\
\hline Mn & 1063.40 & 976.10 & 988.30 & 797.30 & 816.70 & 815.30 \\
\hline $\mathrm{Zn}$ & 105.00 & 93.03 & 99.00 & 77.79 & 78.94 & 72.24 \\
\hline $\mathrm{Sr}$ & 940.50 & 903.70 & 930.90 & 967.50 & 949.60 & 991.20 \\
\hline $\mathrm{Pb}$ & 7.88 & 8.25 & 7.84 & 20.92 & 32.44 & 25.60 \\
\hline $\mathrm{La}$ & 20.86 & 20.09 & 20.68 & 19.47 & 20.39 & 20.16 \\
\hline $\mathrm{Ce}$ & 51.48 & 49.15 & 50.71 & 47.30 & 49.24 & 49.57 \\
\hline $\operatorname{Pr}$ & 7.43 & 7.19 & 7.48 & 7.06 & 7.35 & 7.23 \\
\hline $\mathrm{Nd}$ & 32.75 & 30.91 & 32.00 & 30.03 & 31.52 & 31.03 \\
\hline $\mathrm{Sm}$ & 6.93 & 6.66 & 6.85 & 6.46 & 6.67 & 6.65 \\
\hline $\mathrm{Eu}$ & 2.02 & 1.94 & 2.01 & 1.79 & 1.95 & 1.95 \\
\hline $\mathrm{Gd}$ & 5.46 & 5.18 & 5.37 & 5.03 & 5.26 & 5.15 \\
\hline $\mathrm{Tb}$ & 0.73 & 0.69 & 0.71 & 0.67 & 0.69 & 0.69 \\
\hline Dy & 3.89 & 3.69 & 3.87 & 3.60 & 3.74 & 3.66 \\
\hline Ho & 0.74 & 0.71 & 0.73 & 0.69 & 0.70 & 0.71 \\
\hline $\mathrm{Er}$ & 1.82 & 1.73 & 1.80 & 1.68 & 1.75 & 1.74 \\
\hline $\mathrm{Tm}$ & 0.26 & 0.25 & 0.26 & 0.24 & 0.25 & 0.25 \\
\hline $\mathrm{Yb}$ & 1.59 & 1.57 & 1.65 & 1.54 & 1.57 & 1.58 \\
\hline $\mathrm{Lu}$ & 0.23 & 0.24 & 0.25 & 0.23 & 0.23 & 0.23 \\
\hline$\sum$ REE & 136.18 & 130.00 & 134.35 & 125.78 & 131.31 & 130.58 \\
\hline $\mathrm{La} / \mathrm{Yb}$ & 13.09 & 12.76 & 12.53 & 12.63 & 12.98 & 12.77 \\
\hline$\delta \mathrm{Eu}$ & 0.97 & 0.97 & 0.98 & 0.93 & 0.97 & 0.98 \\
\hline
\end{tabular}




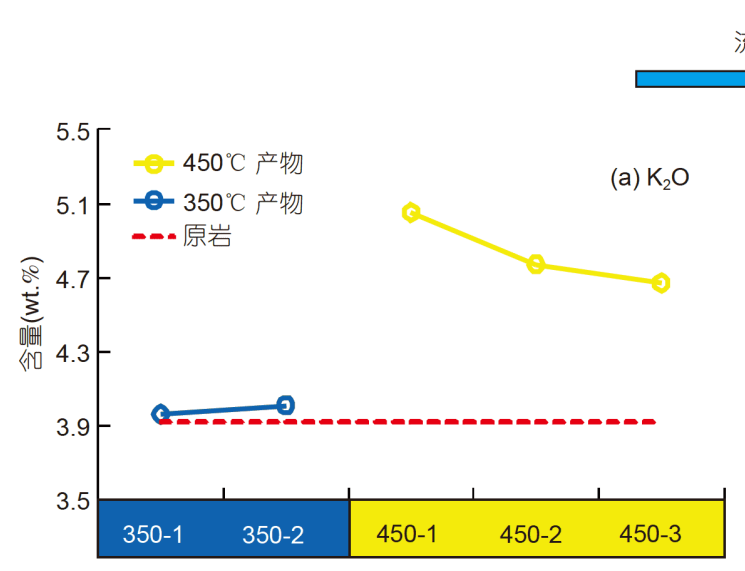

流体流向
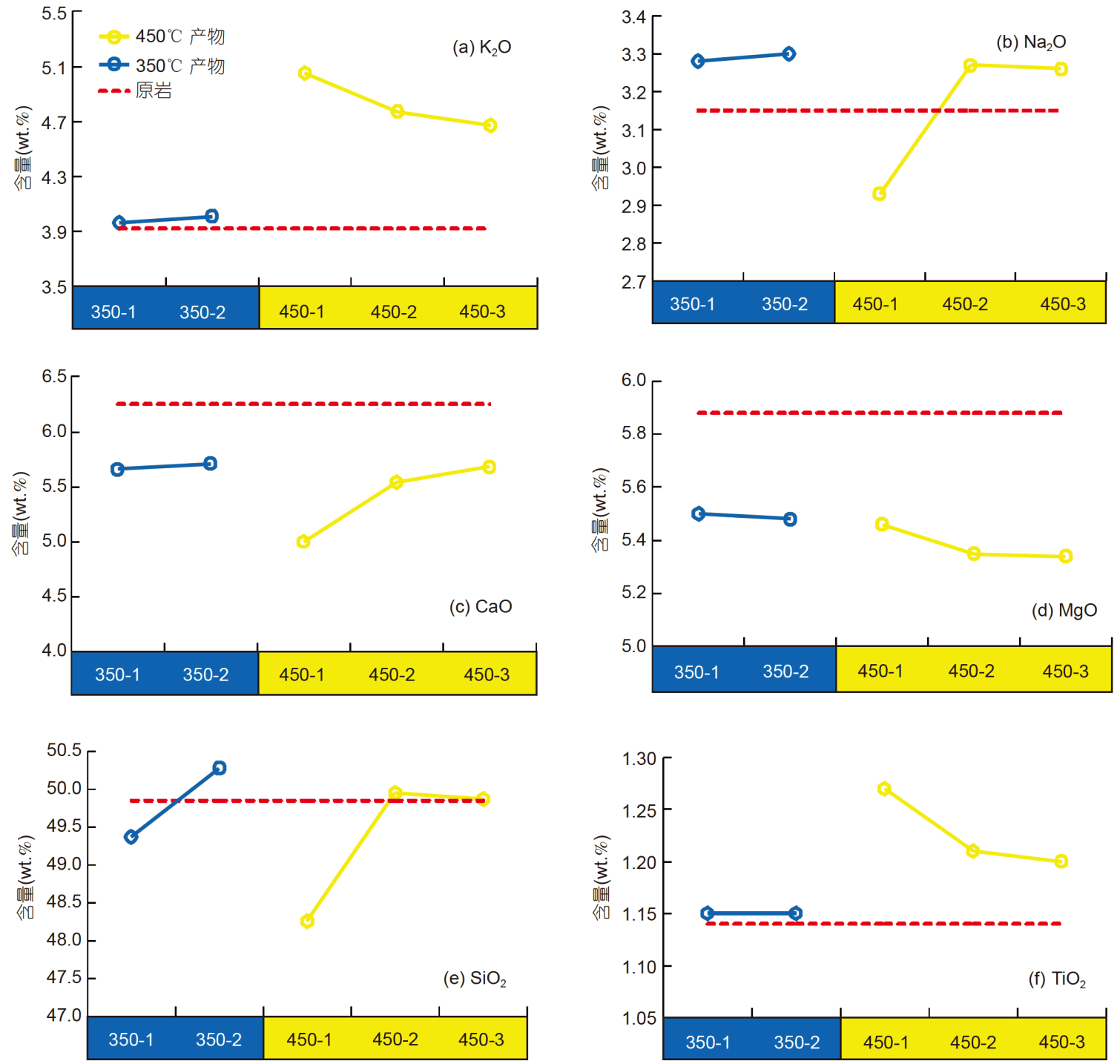

图 6 (网络版彩图)实验产物主量元素含量沿流向变化特征

物中 $\mathrm{Cu}$ 和 $\mathrm{S}$ 的含量均明显增加且在流体入口处达到峰 值(图7a和 $7 b)$, 沿流体流向两者含量呈快速降低趋势, $450^{\circ} \mathrm{C}$ 实验产物中这种变化趋势强于 $350^{\circ} \mathrm{C}$ 实验产物. 实验产物中 $M n$ 和 $Z n$ 均发生淋滤(图 $7 \mathrm{c}$ 和 $7 \mathrm{~d})$, 且 $450^{\circ} \mathrm{C}$ 实验产物淋滤强于 $350^{\circ} \mathrm{C}$ 产物. 沿流体流向, $\mathrm{Mn}$ 淋滤 程度的变化不明显, 而 $\mathrm{Zn}$ 具有不同的变化趋势, $450^{\circ} \mathrm{C}$ 条件下沿流向淋滤变强, $350^{\circ} \mathrm{C}$ 条件下沿流向淋滤变 弱. $450^{\circ} \mathrm{C}$ 实验产物中 $\mathrm{Sr}$ 发生轻微富集(图7e), 而 $350^{\circ} \mathrm{C}$ 实验产物中 $\mathrm{Sr}$ 发生轻微的淋滤. $\mathrm{Pb}$ 含量在 $450^{\circ} \mathrm{C}$ 实验产 物中含量增加且沿流向具有先增加后减少的变化趋势 (图7f), 而在 $350^{\circ} \mathrm{C}$ 实验产物中含量基本保持不变.

\section{3 矿物电子探针分析结果}

对原始岩石样品和实验产物中的单矿物, 如辉 石、长石、绿帘石进行电子探针分析, 探针分析点从 矿物边缘延伸到核部(图8). 分析结果显示, 原始样品 中矿物从核部到边部成分均一, 组成基本不发生变化 (图9a f), 通过对比实验前后矿物边缘到核部成分的 变化可以揭示实验过程中流体和围岩的交代作用.

实验产物中矿物组成发生明显的变化, 靠近矿物 

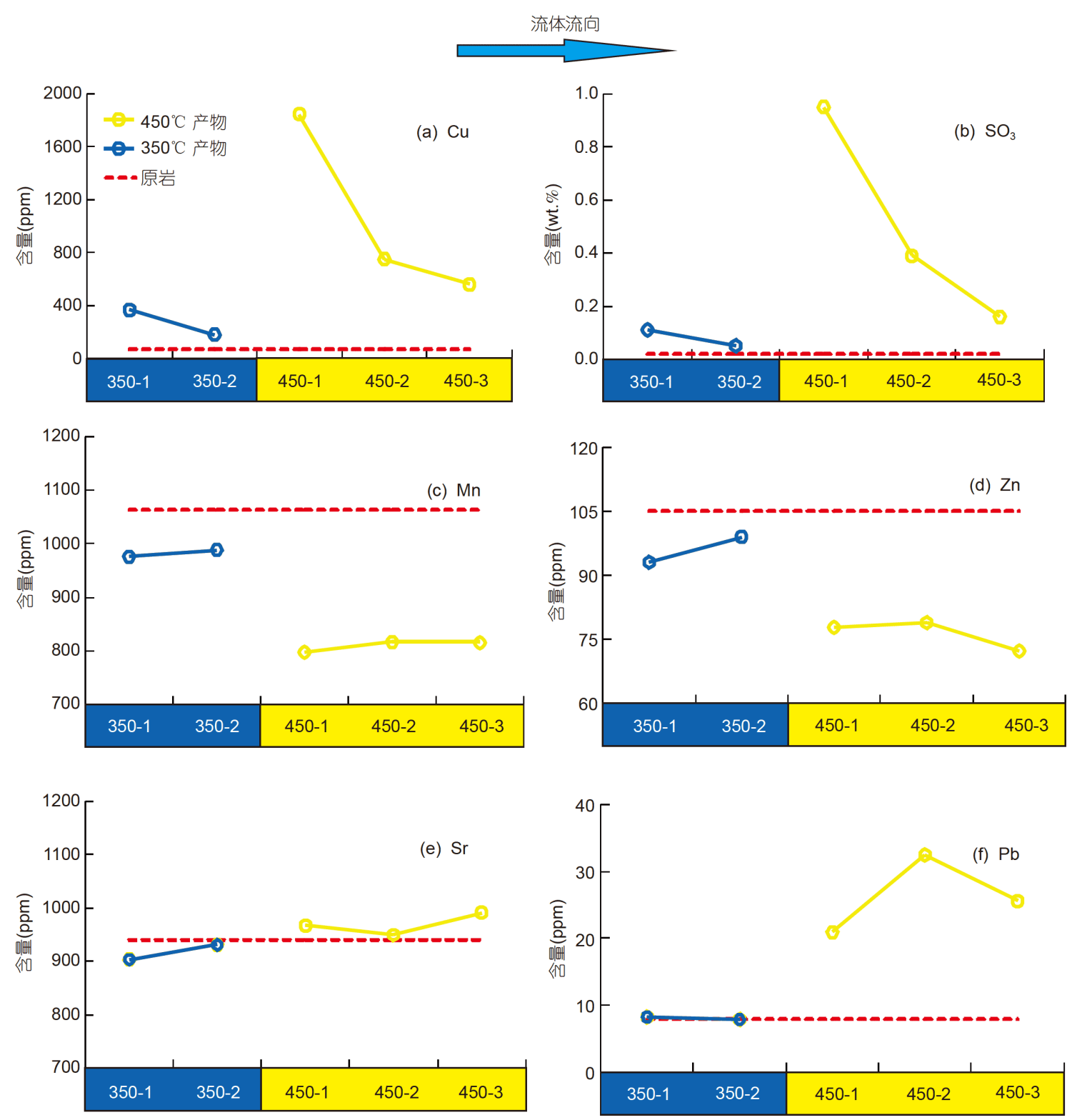

图 7 (网络版彩图)实验产物微量元素含量沿流向变化特征

核部成分均一且保持稳定，边部成分变化明显且含水 量增加. $\mathrm{TiO}_{2}$ 含量变化表明, $350^{\circ} \mathrm{C}$ 实验产物中矿物边 部变化微弱, $450^{\circ} \mathrm{C}$ 实验产物辉石边部 $\mathrm{TiO}_{2}$ 含量具有较 明显降低趋势, 但长石和绿帘石边部 $\mathrm{TiO}_{2}$ 含量明显增 加(图10a和 $10 \mathrm{~b}$ ). $\mathrm{CaO}$ 含量变化表明, 450 和 $350^{\circ} \mathrm{C}$ 实验 产物中辉石和绿窝石边部 $\mathrm{CaO}$ 淋滤异常显著, 倍长石 边部 $\mathrm{CaO}$ 含量也有明显的降低, 更长石由于本身 $\mathrm{CaO}$ 含量很低, 因此其边部 $\mathrm{CaO}$ 含量降低微弱(图 $10 \mathrm{c}$ 和 10d).
$\mathrm{K}_{2} \mathrm{O}$ 和 $\mathrm{Na}_{2} \mathrm{O}$ 含量变化表明, $350^{\circ} \mathrm{C}$ 实验产物更长石 边部 $\mathrm{K}_{2} \mathrm{O}$ 含量降低, 绿帘石和辉石边部 $\mathrm{K}_{2} \mathrm{O}$ 含量微弱增 加; $450^{\circ} \mathrm{C}$ 实验产物中 $\mathrm{K}_{2} \mathrm{O}$ 含量在矿物边部均呈明显增 加趋势(图 $11 \mathrm{a}$ 和 $11 \mathrm{~b}$ ). 350 和 $450^{\circ} \mathrm{C}$ 实验产物中 $\mathrm{Na}_{2} \mathrm{O}$ 含 量在绿帘石边部呈微弱增加趋势, 而在辉石和长石边 部基本保持不变或微弱降低(图11c和 $11 \mathrm{~d}$ ). $\mathrm{SiO}_{2}$ 和 $\mathrm{Al}_{2}$ $\mathrm{O}_{3}$ 含量变化表明, $450^{\circ} \mathrm{C}$ 实验产物中倍长石和绿窝石 边部 $\mathrm{SiO}_{2} 、 \mathrm{Al}_{2} \mathrm{O}_{3}$ 含量均明显降低, 更长石和辉石边部 两者含量变化不明显(图12a和12b). 

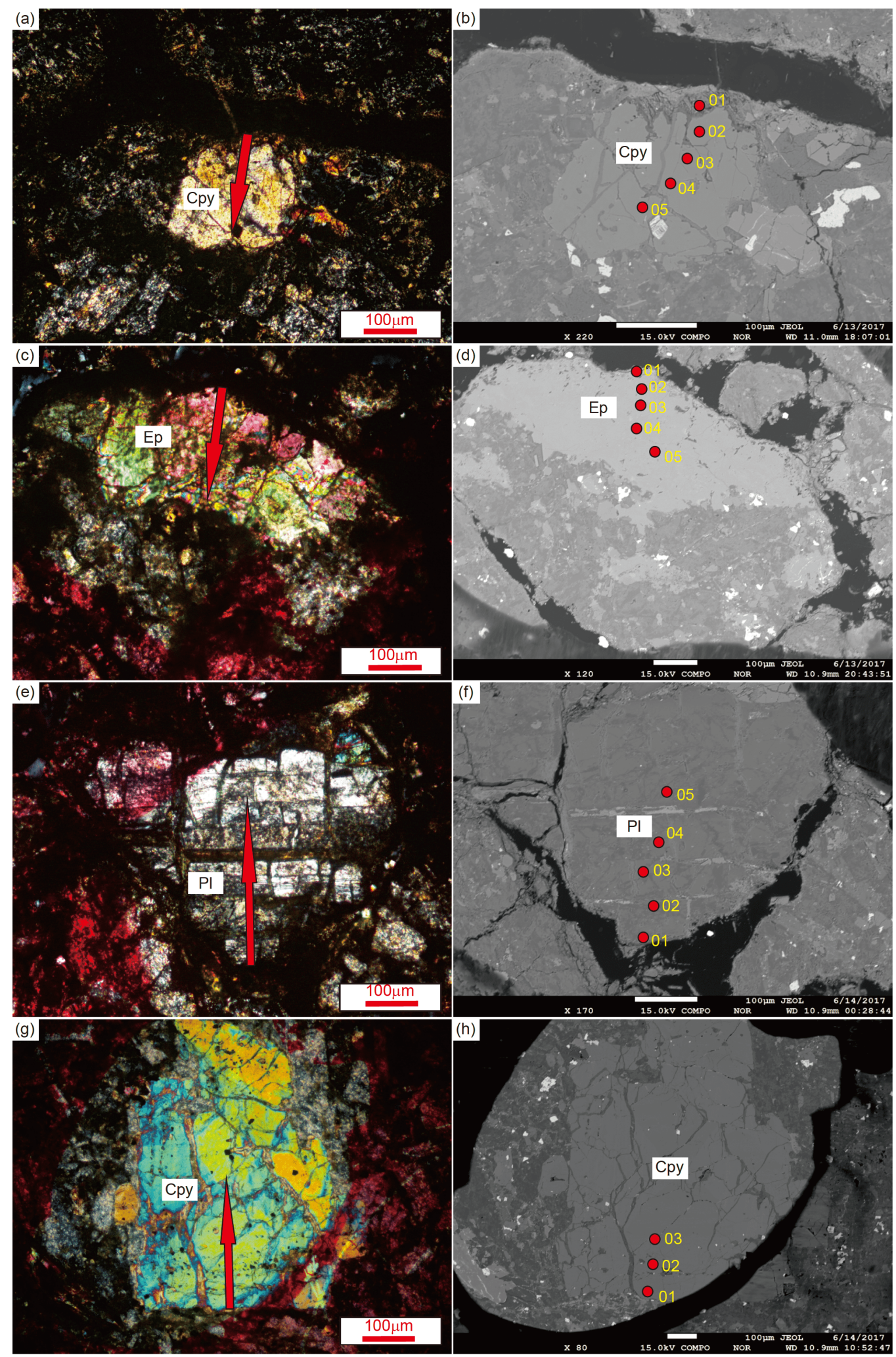

图 8 (网络版彩图)电子探针分析示意图(包括镜下照片和背散射图像)

(a) (f) 实验产物: (a), (b), 辉石; (c), (d), 绿帘石; (e), (f), 倍长石; (g), (h), 原岩中辉石, 箭头方向指示探针分析点延伸方向, 红色点为分析点位置 

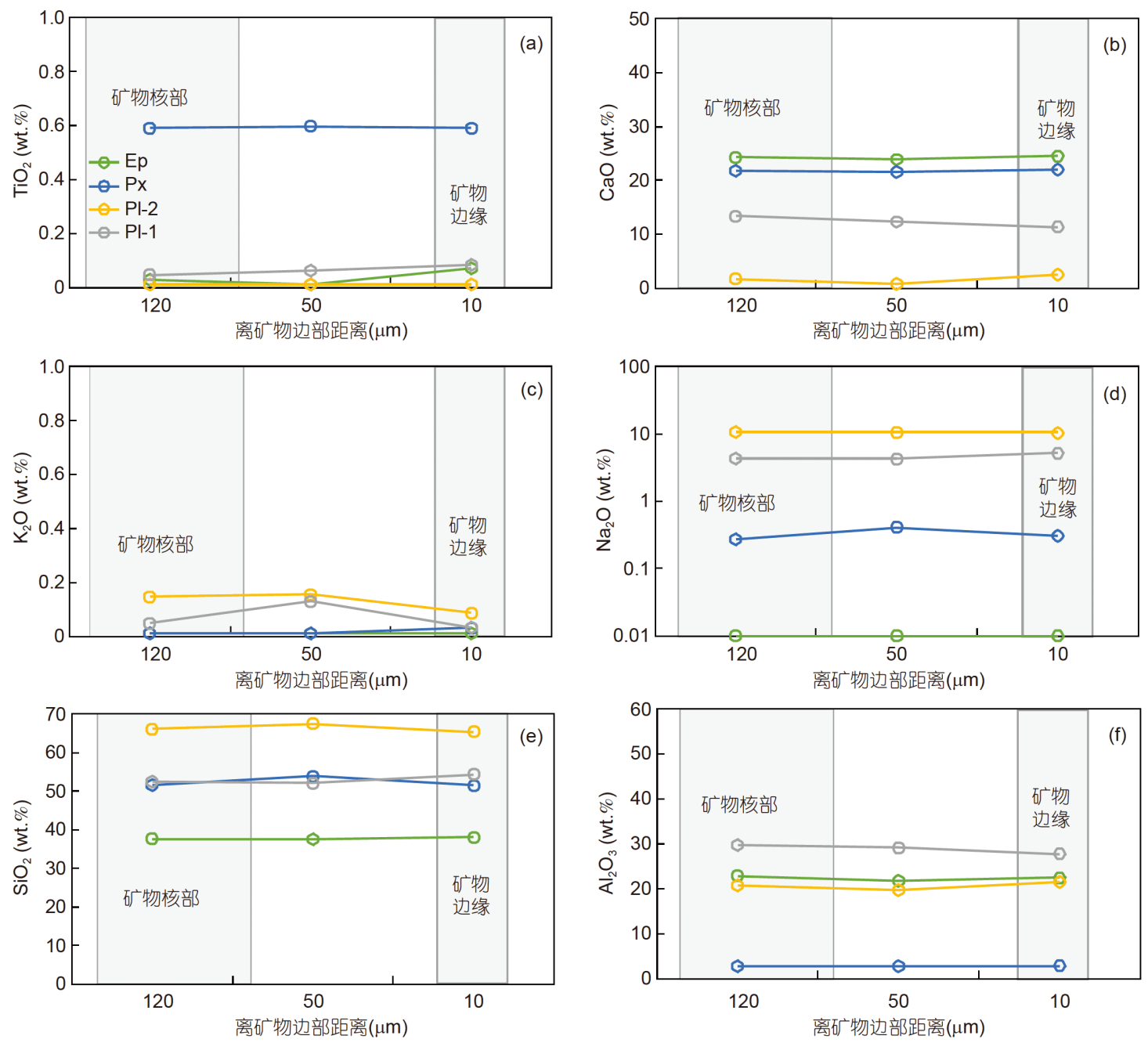

图 9 (网络版彩图)原始岩石样品中单矿物主要成分含量变化

Pl-1, 富Ca长石; Pl-2, 富Na长石; Px, 辉石; Ep, 绿帘石

\section{4 讨论}

\section{1 实验体系内硅酸盐矿物蚀变机理探讨}

全岩分析结果显示，实验产物中不同元素含量较 原岩发生了明显的变化，电子探针分析结果也显示矿 物边部化学组成有明显的改变, 以上结果表明实验体 系内矿物与流体发生了明显的交代反应导致岩石样品 组成发生变化. 前人研究结果显示流体和岩石的交代 反应主要由水-岩界面反应和质量迁移两大过程控制 (张有学, 2010). 流体与硅酸盐矿物的交代反应属于界 面反应控制的过程，具体包括矿物表面 $\mathrm{H}^{+}$吸附、离子 交换和金属离子解吸三个方面，离子置换主要受晶体 内元素化学键类型、 $\mathrm{H}^{+}$浓度和反应活化能的影响
(Murphy等, 1989; 谭凯旋等, 1994; Schott等, 2009). 硅 酸盐矿物内不同元素形成的化学键具有不同键能，因 此打开不同化学键的难易程度不同，导致矿物内元素 的非一致性溶解(王玉荣等, 2000; Schott等, 2009).

前人实验研究表明，发生在流体和矿物相界面的 反应主要是流体内的 $\mathrm{H}^{+}$或其他离子与硅酸盐中阳离 子逐渐发生置换反应，并最终导致硅酸盐格架发生改 变和破坏的一系列过程(Oelkers等, 1994). 通过对玄武 质玻璃、钾长石、钠长石和辉石的溶解实验研究证 明，流体对硅酸盐的交代淋滤过程主要涉及三个阶段 (Gautier等，1994; Oelkers，2001；Gislason和Oelkers， 2003): (1) 首先在水-岩界面, +1 价和 +2 价金属元素和 流体内 $\mathrm{H}^{+}$发生替换导致这部分金属离子发生淋滤; (2) 

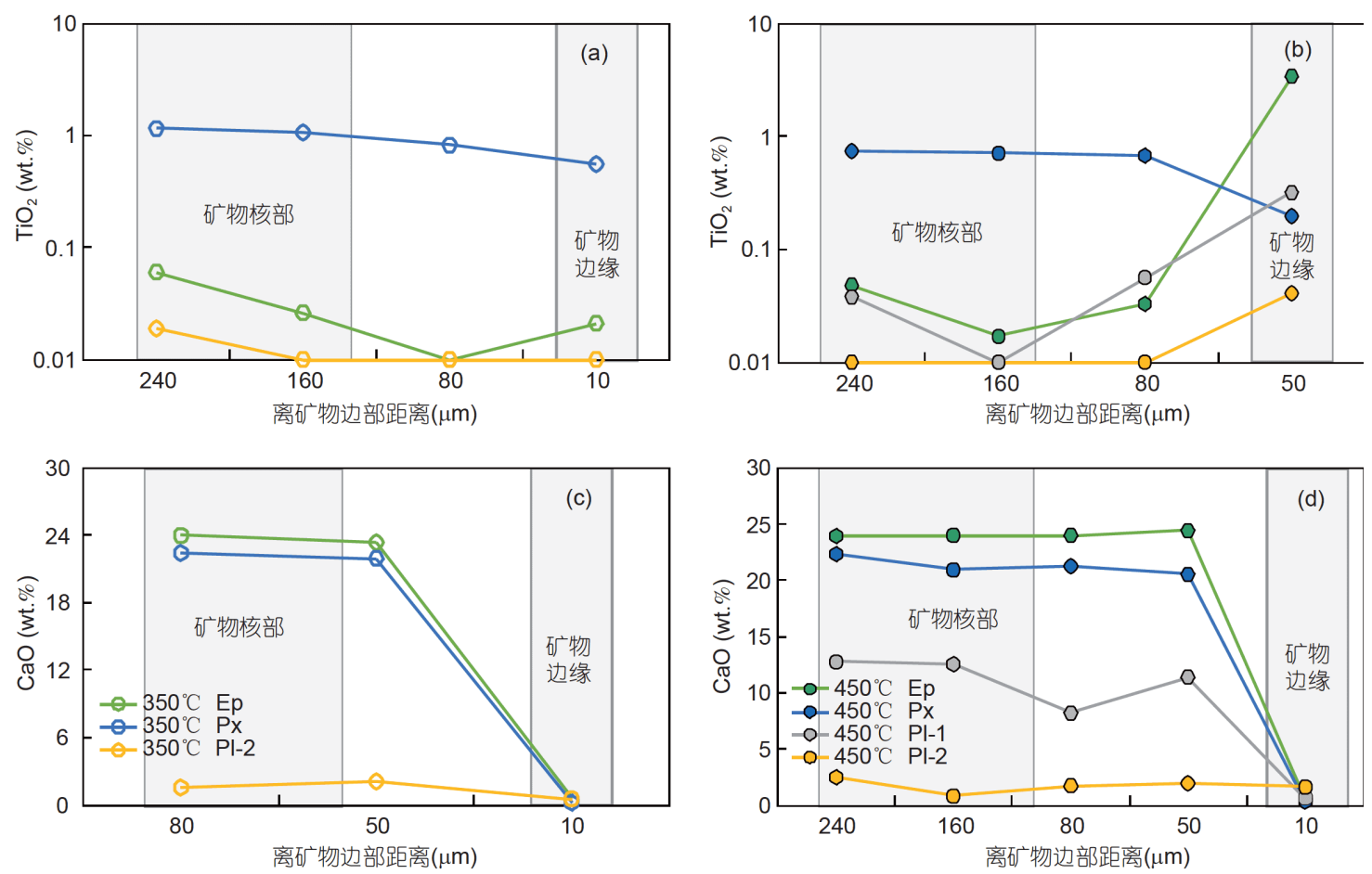

图 10 (网络版彩图) $350{ }^{\circ} \mathrm{C}$ 实验产物 $((\mathrm{a}),(\mathrm{c}))$ 和 $450^{\circ} \mathrm{C}$ 实验产物 $((\mathrm{b}),(\mathrm{d}))$ 中单矿物 $\mathrm{TiO}_{2}$ 和 $\mathrm{CaO}$ 含量变化 Pl-1, 倍长石; Pl-2, 更长石; Px, 辉石; Ep, 绿帘石

其次是 $\mathrm{H}^{+}$替换结构 $\mathrm{Al}$ 使硅酸盐格架开始发生变化; (3) 最后水分子吸附导致 $\mathrm{Si}-\mathrm{O}$ 键断裂和 $\mathrm{Si}$ 释放，硅酸盐结 构发生破坏(若矿物相贫 $\mathrm{Al}$, 则直接发生水分子吸附导 致 $\mathrm{Si}-\mathrm{O}$ 键断裂和 $\mathrm{Si}$ 的释放).

硅酸盐中 $\mathrm{Si}-\mathrm{O}$ 键更倾向于极性键性质，在温度 $T \geq 300^{\circ} \mathrm{C}$ 时，水的物化性质发生变化并且氢键网格的 破坏会导致具极性键的物质易发生水化, $\mathrm{Si}-\mathrm{O}$ 键易被 打开和发生Si淋滤(黄文斌等, 2011), 本次研究中全岩 分析结果也显示实验产物中 $\mathrm{Si}$ 均发生了明显的淋滤, 且在较高温度条件下淋滤更强. 电子探针分析结果也 显示 $450^{\circ} \mathrm{C}$ 实验产物中倍长石和绿帘石边部 $\mathrm{Si}$ 和 $\mathrm{Al}$ 含 量均降低，核部到边部两者 $\mathrm{mol}_{\mathrm{Si}} / \mathrm{mol}_{\mathrm{Al}}$ 比值均呈增加 趋势，分别从3.32升至32.54和2.83升至5.26，这表明以 上两种矿物边部 $\mathrm{Al}$ 和 $\mathrm{Si}$ 均发生淋滤且 $\mathrm{Al}$ 的淋滤更强 (图13a和13b). 前人进行的玄武质玻璃和铝硅酸盐矿 物在低温(低于 $100^{\circ} \mathrm{C}$ )酸性条件下的溶解实验显示, $\mathrm{Al}$ 和 $\mathrm{Si}$ 的淋滤量具有很好的线性关系，表明两种元素的 释放紧密相关，该过程可能的溶解机制是硅酸盐中首 先 $\mathrm{Al}$ 发生淋滤导致最邻近的 $\mathrm{Si}-\mathrm{O}$ 键断裂和 $\mathrm{Si}$ 的释放 (Oelkers等, 1994; Oelkers和Schott, 2001), 而本次实验
产物中的长石及绿帘石从核部到边部 $\mathrm{Al}$ 和 $\mathrm{Si}$ 含量变化 并无明显的线性关系(图13a和13b), 表明本次实验体 系硅酸盐内 $\mathrm{Al}$ 和 $\mathrm{Si}$ 的释放并非线性相关. 我们由此推 测斑岩铜矿成矿体系中硅酸盐围岩的溶解可能是多因 素控制的复杂过程, 影响因素除温度和 $\mathrm{pH}$ 外还可能受 流体盐度和化学组成的控制.

结合前人研究的理论基础(Oelkers等, 1994; Oelkers和Schott, 2001; Gislason和Oelkers，2003)及本次实 验产物分析结果, 即以实验产物中元素含量的变化幅 度为依据(如 $450^{\circ} \mathrm{C}$ 实验产物中矿物边缘 $\mathrm{K}$ 含量增加显 著, Ca淋滤明显, $\mathrm{Si}$ 和 $\mathrm{Al}$ 含量也有一定的降低), 可以揭 示本次实验体系中水-岩反应机制: 即流体中 $\mathrm{H}^{+}$和碱金 属离子易进入矿物内部发生选择性置换, 首先是一价 和二价阳离子更易被置换和淋滤(图14a)，其次是 $\mathrm{Si}$ 、 $\mathrm{Al}$ 的淋滤及硅酸盐矿物结构的变化(图14b), 其中 $\mathrm{Al}$ 和 $\mathrm{Si}$ 的淋滤没有明显的线性关系. 根据过渡态理论, 高温 使得体系活化分子数提升, 导致矿物表面吸附的 $\mathrm{H}^{+}$与 内部金属阳离子更易发生置换反应(Aagaard和Helgeson, 1982), 因此高温条件下反应更加强烈, 导致 $450^{\circ} \mathrm{C}$ 实验产物中元素的富集和亏损程度相比于 $350^{\circ} \mathrm{C}$ 实验 

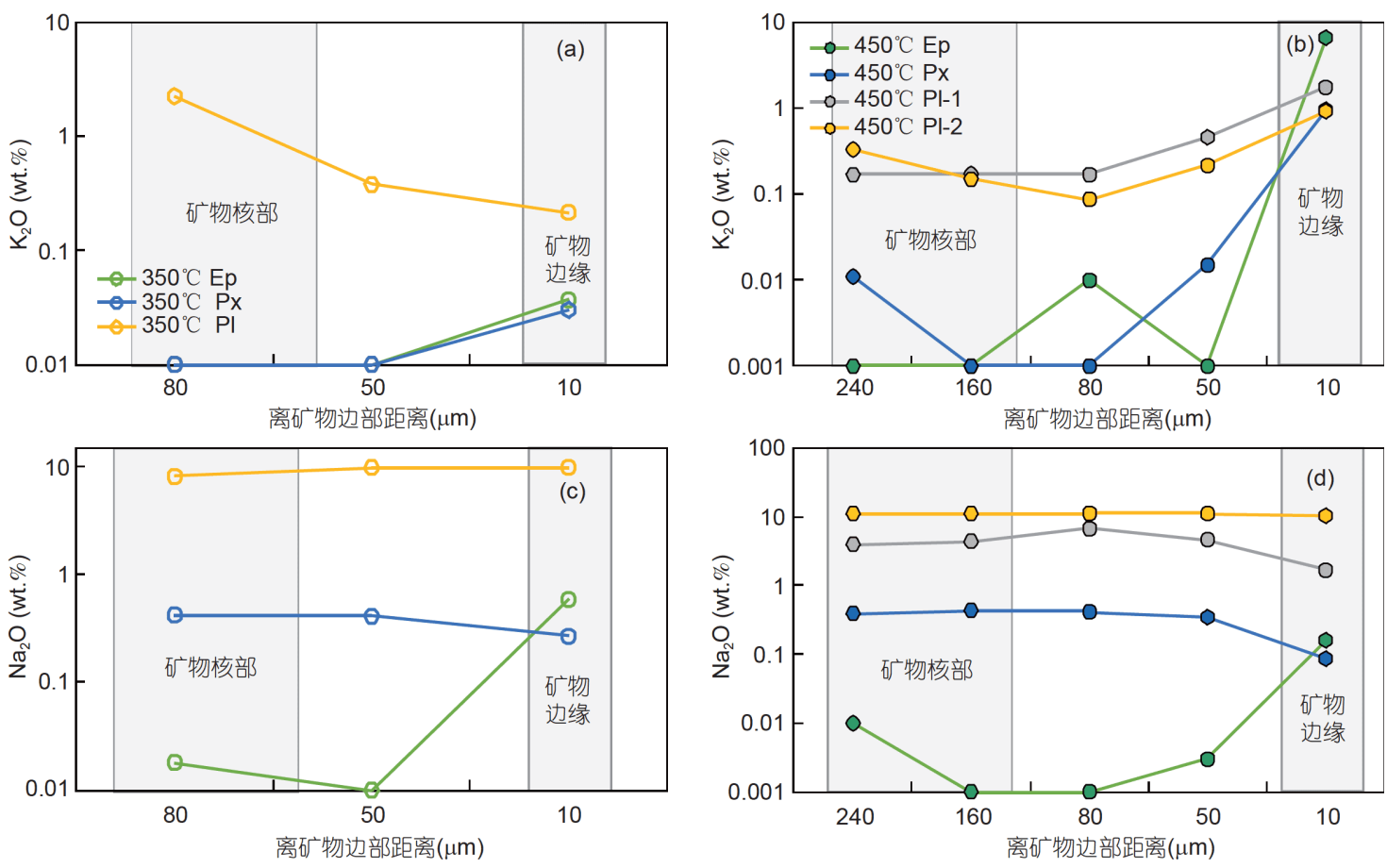

图 11 (网络版彩图) $350{ }^{\circ} \mathrm{C}$ 实验产物 ((a), (c)) 和 $450{ }^{\circ} \mathrm{C}$ 实验产物 ((b), (d)) 中单矿物 $\mathrm{K}_{2} \mathrm{O}$ 和 $\mathrm{Na}_{2} \mathrm{O}$ 含量变化 Pl-1, 倍长石; Pl-2, 更长石; Px, 辉石; Ep, 绿帘石
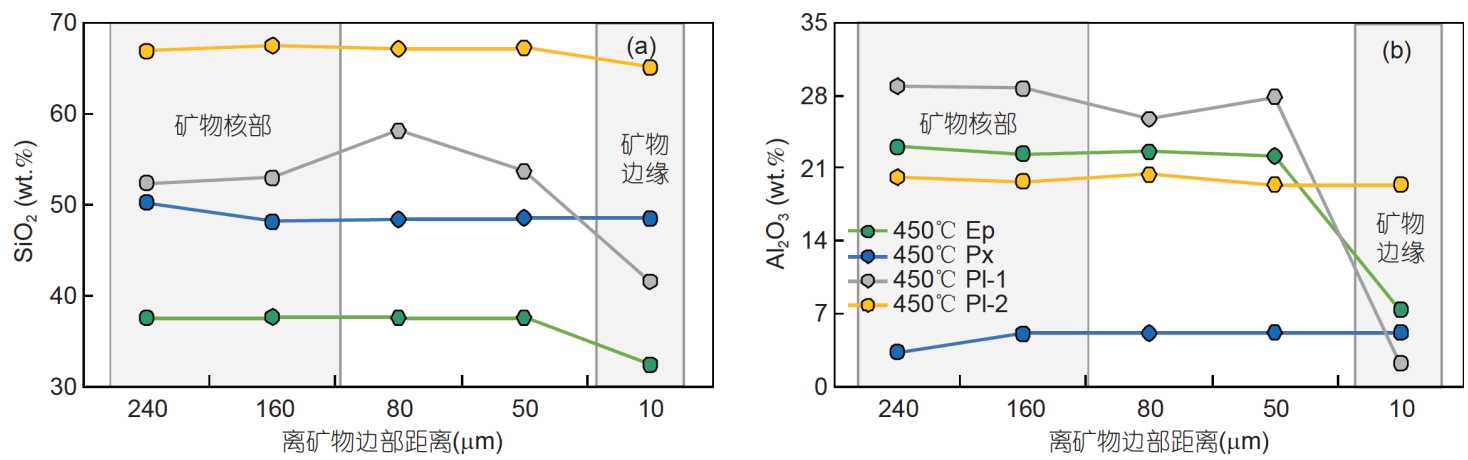

图 12 (网络版彩图) $4500^{\circ} \mathrm{C}$ 实验产物中单矿物 $\mathrm{SiO}_{2}(\mathrm{a})$ 和 $\mathrm{Al}_{2} \mathrm{O}_{3}(\mathrm{~b})$ 含量变化

Pl-1, 倍长石; Pl-2, 更长石; Px, 辉石; Ep, 绿帘石

产物更为明显.

通过对比反应产物中元素含量相对于原始样品的 变化幅度，可以近似推断出热液体系内火山围岩和成 矿流体反应过程中元素的迁移倾向性和活动性强弱, 具体计算方法是对实验产物中元素含量的变化沿流体 流动方向进行积分并除以柱状产物的长度，计算出产 物中每种元素含量增减的幅度，以此为依据来判断该 种元素的迁移倾向性和活动性强弱顺序. 对于易发生 淋滤的主量元素和微量元素，根据实验产物中其含量
降低幅度的大小，淋滤能力由强到弱分别为 $\mathrm{Ca}$ 、 $\mathrm{Mg} 、 \mathrm{Si} 、 \mathrm{Al}$ 和 $\mathrm{Mn} 、 \mathrm{Zn}$; 对于易进入硅酸盐矿物晶格 的主量元素和微量元素, 根据实验产物中其含量增加 幅度的大小，其置换矿物内部元素能力由强到弱依次 为， $\mathrm{K} 、 \mathrm{Na} 、 \mathrm{Ti}$ 和 $\mathrm{Sr} 、 \mathrm{~Pb}$. 前人进行的封闭体系玄武 岩-卤水(海水)实验研究结果显示, 岩石样品主要组成 的变化也并非按化学计量数进行, 如固相中 $\mathrm{K} 、 \mathrm{Ca} 、$ $\mathrm{Al}$ 和 $\mathrm{Si}$ 等主量元素发生非一致性淋滤现象，其中+1价 和 +2 价元素活动性较强且含量变化显著, 而 $\mathrm{Al}$ 和 $\mathrm{Si}$ 的 

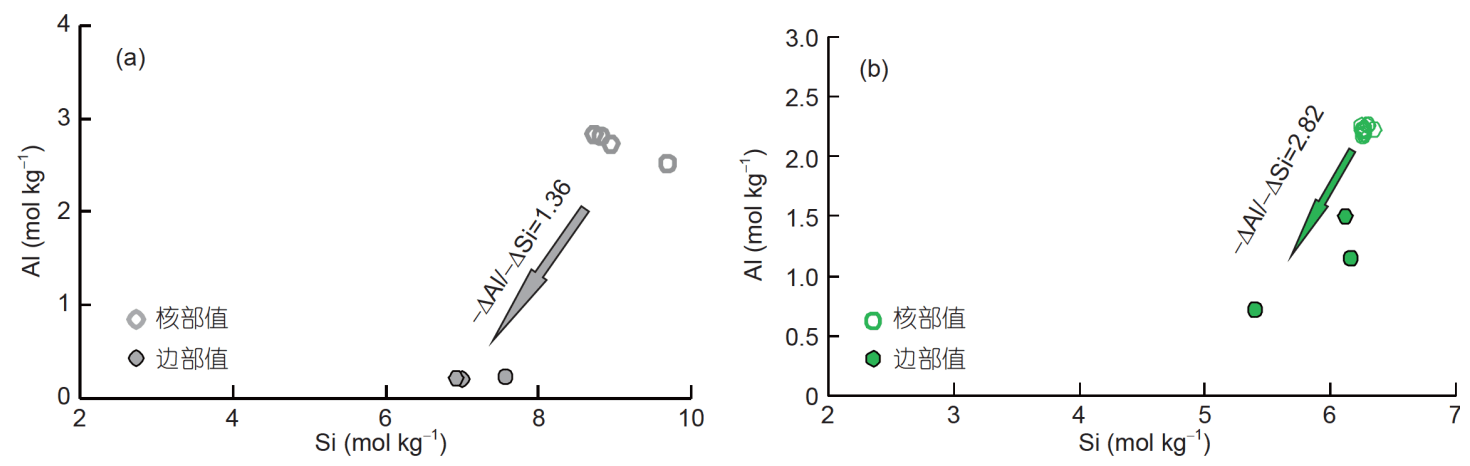

图 $13450{ }^{\circ} \mathrm{C}$ 实验产物中倍长石(a)和绿窝石(b)核部及边部 $\mathrm{Si} 、 \mathrm{Al}$ 含量变化 $-\Delta \mathrm{Si}$ 和 $-\Delta \mathrm{Al}$ 表示矿物边部淋滤量
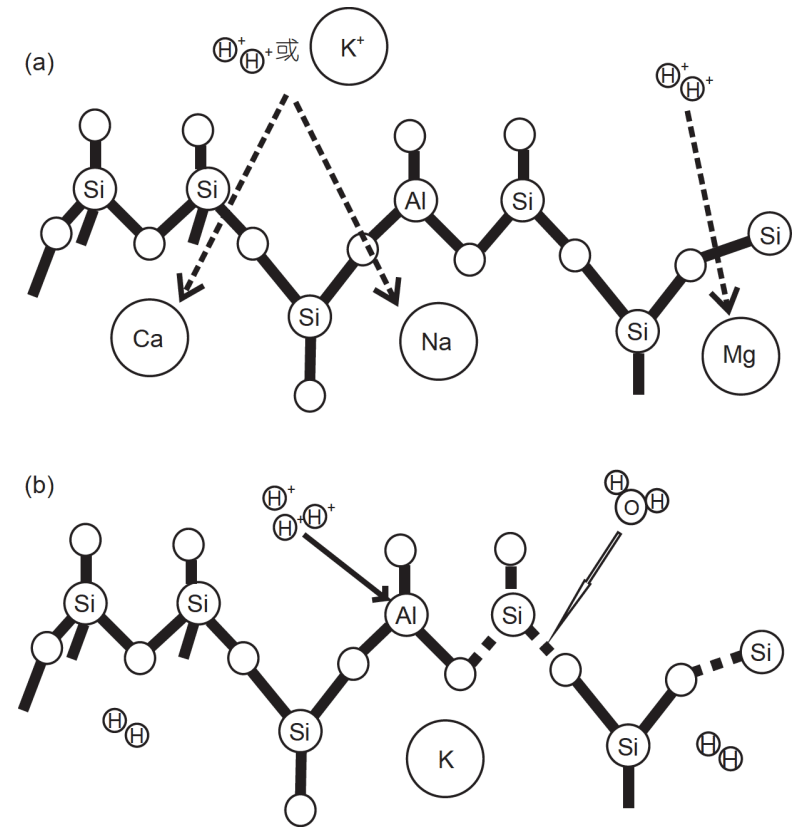

图 14 实验体系水-岩交代反应过程示意图

(a) $\mathrm{H}^{+}$和 $\mathrm{K}^{+}$进入矿物晶格置换其他低价金属阳离子; (b) $\mathrm{H}^{+}$置换 $\mathrm{Al}$ 及 $\mathrm{Si}$ 的释放. 修改自Oelkers和 Schott(2001)

活动性较弱, 但区别是固相中 $\mathrm{Ca} 、 \mathrm{~K} 、 \mathrm{Si}$ 和 $\mathrm{Al}$ 发生淋 滤而Na、Mg含量增加(Mott1和Holland, 1978, 党志和 侯瑛，1995; 刘玉山和张桂兰，1996; 胡书敏等, 2010; Gudbrandsson等，2011)，这与我们在流动体系中模拟 斑岩系统内热液和中基性火山围岩作用的实验结果存 在一定差异.

\section{2 斑岩铜矿系统钾化与钠化蚀变机制}

钾硅酸盐化带是斑岩铜矿床中普遍发育的高-中
温蚀变带, 钾化带内流体包裹体均一温度的范围介于 $250^{\circ} \mathrm{C}$ 到 $\geq 600^{\circ} \mathrm{C}$, 但原生流体包裹体均一温度一般高 于 $400^{\circ} \mathrm{C}$ (Sillitoe, 2010; Bondar等, 2014), 表明其是由 高温岩浆热液交代侵入岩体顶部或临近围岩形成，一 般位于斑岩铜矿系统的核部，不同岩石类型发育的钾 化带矿物组合虽有差异, 但主要矿物组合包括石英、 钾长石、黑云母、硬石亳、磁铁矿和铜铁硫化物等 (Sillitoe, 1973, 2010). 全球范围内许多大型斑岩铜矿的 成矿主体均分布在钾化带内, 如Bingham斑岩 $\mathrm{Cu}-\mathrm{Au}$ (Mo)矿床的 $\mathrm{Cu}-\mathrm{Au}$ 矿化均与五种侵入体的钾硅酸盐化 带密切相关, 其中最主要的致矿岩体是早期石英二长 斑岩侵入体, 其含有最高品位的矿化和最显著的钾化 蚀变特征, 两者具有紧密关系(Redmond等, 2004; Redmond和Einaudi, 2010; Landtwing等, 2010), 因此对斑岩 系统高-中温蚀变特征及其在矿化过程中的作用进行 实验研究具有重要意义. 针对斑岩铜矿高温蚀变带的 形成机制, 前人在封闭水-岩体系内进行了一系列实验 研究, 通过研究实验产物中元素的迁移富集行为、矿 物组成变化和相变的边界条件, 来揭示高温蚀变机制 及主要的控制因素(Hemley, 1959; Montoya和Hemley, 1975; Sverjensky等, 1991; Haselton等, 1995). 研究结果 表明在高温、高 $\mathrm{K}^{+} / \mathrm{H}^{+}$条件下, 易发生钾化蚀变且在该 条件下有利于钾长石稳定存在, 而高温、高 $\mathrm{Na}^{+} / \mathrm{H}^{+}$条 件下，易发生钠化蚀变(Hemley和Jones，1964; Frank 等, 1998; Frank和Vaccaro, 2012), 但在流动体系内温 度、 $\mathrm{K}^{+}$和 $\mathrm{Na}^{+}$含量同时对发生钾化和钠化蚀变的影响 程度, 前人并没有进行更细致的研究.

本次实验研究的初始流体具有恒定的 $\mathrm{Na}^{+} / \mathrm{K}^{+}$比 值, 可以探讨不同温度条件下钾化与钠化蚀变的相互 
关系. 实验产物分析结果显示, $450^{\circ} \mathrm{C}$ 实验产物中 $\mathrm{K}_{2} \mathrm{O}$ 的含量增加显著, 表明样品可能发生较强的钾化蚀变, 电子探针分析结果也显示 $450^{\circ} \mathrm{C}$ 产物矿物边部相对于 核部 $\mathrm{K}_{2} \mathrm{O}$ 含量均有明显的增加, 进一步证实了钾化蚀 变的发生. $350^{\circ} \mathrm{C}$ 实验产物 $\mathrm{K}_{2} \mathrm{O}$ 的含量变化很微弱, 电 子探针分析结果同样显示矿物边部 $\mathrm{K}_{2} \mathrm{O}$ 含量基本保持 不变, 表明温度可能是导致钾化蚀变的重要因素. 沿流 体流向, 不同实验产物中 $\mathrm{K}_{2} \mathrm{O}$ 含量增加幅度均有降低 趋势，这是由于流体上游方向发生钾化导致流体中 $\mathrm{K}^{+}$浓度降低造成. 我们分别将 $450^{\circ} \mathrm{C}$ 和 $350^{\circ} \mathrm{C}$ 实验产物 组成与原始岩石样品组成进行对比, $450^{\circ} \mathrm{C}$ 实验产物 中 $\mathrm{K}_{2} \mathrm{O}$ 含量的增加幅度是 $350^{\circ} \mathrm{C}$ 实验产物增加幅度的 近 30 倍, 而 $450^{\circ} \mathrm{C}$ 实验初始流体中 $\mathrm{K}^{+}$浓度相比 $350^{\circ} \mathrm{C}$ 实 验初始流体只提高了一倍, 而且反应过程中两者水-岩 比值接近相等. 因此相比 $350^{\circ} \mathrm{C}$ 实验产物, $450^{\circ} \mathrm{C}$ 实验产 物中 $\mathrm{K}_{2} \mathrm{O}$ 含量的增加幅度远远大于其实验初始流体 $\mathrm{K}^{+}$浓度的增加幅度, 由此我们推测更高的反应温度可 能是控制钾化蚀变最主要的因素. 流体包裹体显微测 温结果显示, 斑岩成矿系统钾化带中原生流体包裹体 均一温度几乎均在 $400^{\circ} \mathrm{C}$ 以上(Sillitoe, 2010), 也显示 了相对高温条件下更有利于钾化蚀变的发生.

实验分析结果显示, 靠近流体中心(靠近流体入 口), 实验产物中 $\mathrm{Na}_{2} \mathrm{O}$ 含量具有不同变化趋势, $450^{\circ} \mathrm{C}$ 实验产物中 $\mathrm{Na}_{2} \mathrm{O}$ 在靠近流体中心发生明显的淋滤之 后沿流体流向呈微弱增加, 而 $350^{\circ} \mathrm{C}$ 实验产物中 $\mathrm{Na}_{2} \mathrm{O}$ 含量总体呈微弱增加趋势. 前人实验研究表明, 高 温、高 $\mathrm{Na}^{+} / \mathrm{H}^{+}$条件下易发生钠化蚀变(Hemley和Jones, 1964), 但本次实验结果显示 $450^{\circ} \mathrm{C}$ 和 $350^{\circ} \mathrm{C}$ 产物中 $\mathrm{Na}_{2} \mathrm{O}$ 含量增加均很微弱, 这表明实验温度段不易发生钠化 蚀变. $4500^{\circ} \mathrm{C}$ 实验初始流体 $\mathrm{Na}^{+}$浓度明显高于 $350^{\circ} \mathrm{C}$ 实 验初始流体, 但在更高温度、更高的 $\mathrm{Na}^{+}$浓度条件下 并未导致更强烈的钠化蚀变, 而是两者具有相近且微 弱的钠化蚀变程度, 这与前人实验研究结果即在高 温、高 $\mathrm{Na}^{+}$浓度条件下更易发生钠化蚀变存在一定的 差异. 对比不同实验初始流体 $\mathrm{Na}^{+}$浓度和产物中 $\mathrm{Na}$ 含 量的变化幅度表明, $450^{\circ} \mathrm{C}$ 和 $350^{\circ} \mathrm{C}$ 条件下围岩均可以 发生轻微钠化蚀变, 但 $450^{\circ} \mathrm{C}$ 实验产物靠近流体中心 $\mathrm{Na}$ 先发生淋滤后呈轻微富集, 这表明不同温度条件下 发生同等程度钠化所需的 $\mathrm{Na}^{+}$浓度不同. $450^{\circ} \mathrm{C}$ 条件下 体系内发生一定的钠化蚀变需要更高的 $\mathrm{Na}^{+}$浓度, 而 $350^{\circ} \mathrm{C}$ 条件下发生同等程度钠化蚀变所需 $\mathrm{Na}^{+}$浓度相对
较低, 这也表明不同温度条件下体系内发生钠化蚀变 的难易程度存在差异.

造成实验产物中 $\mathrm{K}_{2} \mathrm{O}$ 和 $\mathrm{Na}_{2} \mathrm{O}$ 含量变化差异的原因 可能是体系内同时发生钾化和钠化蚀变, $\mathrm{K}^{+}$和 $\mathrm{Na}^{+}$在 硅酸盐矿物内相互替代或对其他主要阳离子进行替代 (如Ca), 这两种元素的替换在同一体系内呈竞争关系. 由于这两种元素在同一体系内的不相容性(杜乐天, 1986), 因此两者表现出不同的置换倾向性. 实验结果 显示, $450^{\circ} \mathrm{C}$ 条件下 $\mathrm{K}^{+}$更易进入硅酸盐矿物晶格而导 致钾化占据绝对主导, 钠化处于次要地位. $350^{\circ} \mathrm{C}$ 条件 下钾化程度显著降低, 表明该温度条件下 $\mathrm{K}^{+}$不易进入 矿物晶格, 而在该条件下 $\mathrm{Na}^{+}$相对较易进入矿物晶格, 因此在较低的 $\mathrm{Na}^{+}$浓度下围岩可以发生同等程度的钠 化蚀变. 从 $350^{\circ} \mathrm{C}$ 到 $450^{\circ} \mathrm{C}$ 实验, 实验初始流体均以 $\mathrm{Na}^{+}$为主 $\left(450^{\circ} \mathrm{C}\right.$ 和 $350^{\circ} \mathrm{C}$ 实验初始流体的 $\mathrm{mol}_{\mathrm{Na}+} / \mathrm{mol}_{\mathrm{K}+}$ 值均为 2.6), 但 $450^{\circ} \mathrm{C}$ 实验产物中 $\mathrm{K}_{2} \mathrm{O}$ 的增加量是 $\mathrm{Na}_{2} \mathrm{O}$ 增量的近 12 倍, 这表明即使流体中含有较高的 $\mathrm{Na}^{+}$浓 度, 在较高温度条件下体系仍以钾化蚀变占主导而钠 化蚀变较微弱. 斑岩铜矿是高温岩浆热液演化的直接 产物, 系统核部普遍发育高温钾化带, 而钠化带在斑 岩铜矿系统内部往往缺失或不发育(Sillitoe, 2010), 实 验结果则很好的验证了这一现象, 即中-高温体系存在 一定浓度的 $\mathrm{K}^{+}$时 $\mathrm{Na}^{+}$的活动性会受到明显的抑制作用, 从而使钠化带缺失. 综上所述, $450^{\circ} \mathrm{C}$ 条件下体系内钾 化蚀变占据绝对主导, 钠化蚀变较微弱; $350^{\circ} \mathrm{C}$ 条件下 钾化程度明显变弱, 而钠化程度相对增强但依然微弱. 通过对比不同实验初始流体中 $\mathrm{K}^{+}$和 $\mathrm{Na}^{+}$浓度及实验产 物中 $\mathrm{K}_{2} \mathrm{O}$ 和 $\mathrm{Na}_{2} \mathrm{O}$ 增量的关系表明, 温度是控制钾化蚀 变的重要因素, 而发生同等程度钠化, 较高温度条件 下所需的 $\mathrm{Na}^{+}$浓度高于较低温度下所需浓度(高温下 $\mathrm{K}^{+}$会显著影响 $\mathrm{Na}^{+}$的行为), 以上因素可能是导致斑岩 铜矿系统内普遍发育钾化带而一般缺失钠化带的重要 原因.

但值得注意的是, 部分斑岩铜矿系统根部发育有 钠-钙化蚀变带, 如Yerington斑岩 $\mathrm{Cu}$ 矿和Pebble斑岩 Cu-Au-Mo矿等(Carten, 1986; Seedorff等, 2008). 通常 这些斑岩铜矿系统内钠-钙化蚀变和钾化蚀变近乎同 时形成, 但钠-钙化蚀变带一般位于钾化带下部, 更加 靠近系统根部. 由于这两种蚀变带所处位置不同, 因此 形成两种不同蚀变类型流体的热力学性质和演化路径 有比较大的差异, 我们推测深部钠-钙化带的形成可能 
与流体的温压状态和演化路径有关，尤其是当初始流 体中 $\mathrm{K}^{+}$浓度较低时这种现象更易发生．岩浆热液导致 围岩钠化蚀变也有另一种解释(Pollard, 2001), 其主要 认为相比于富 $\mathrm{Cl}^{-}$流体, 富 $\mathrm{CO}_{2}$ 的岩浆热液不混溶作用 可以导致流体中 $\mathrm{Na} /(\mathrm{Na}+\mathrm{K})$ 比值升高，进一步导致围 岩的钠化蚀变, 当斑岩系统中富 $\mathrm{CO}_{2}$ 流体出现时可能 会导致这种现象的发生，但事实上多数斑岩矿床的流 体包裹体研究工作并未发现显著的富 $\mathrm{CO}_{2}$ 包裹体的存 在. 因此要揭示斑岩铜矿系统根部钠-(钙)化蚀变的机 制需要今后更为系统的实验研究工作.

\section{3 主微量元素迁入、迁出及其对蚀变矿化的 影响}

\subsection{1 非成矿元素的迁入和迁出}

实验产物分析结果显示, $450^{\circ} \mathrm{C}$ 和 $350^{\circ} \mathrm{C}$ 实验产物 中 $\mathrm{CaO}$ 均发生明显淋滤，且较高温度条件下淋滤更强， 这表明温度是导致围岩 $\mathrm{Ca}$ 活化淋滤的重要因素. 电子 探针分析结果也显示富 $\mathrm{Ca}$ 长石、辉石和绿帘石边缘 $\mathrm{CaO}$ 发生显著的淋失. 对 Butte斑岩 $\mathrm{Cu}-\mathrm{Mo}$ 矿床不同蚀 变带内的原生流体包裹体进行LA-ICP-MS分析显示, 代表原始岩浆出溶流体的高温低盐度流体包裹体中 $\mathrm{Ca}$ 含量低于检测限 $(\mathrm{Ca}$ 的检出限比其他元素高很多), 而晚期石英脉中流体包裹体内 $\mathrm{Ca}$ 含量明显高于检测 限(Rusk等, 2004), 这表明岩浆出溶的原始流体经过演 化其中 $\mathrm{Ca}$ 含量有显著增加趋势，推测可能是高温条件 下含矿热液淋滤围岩导致流体中 $\mathrm{Ca}$ 含量提升，本次实 验结果与该现象相符且进一步验证了 $\mathrm{Ca}$ 淋滤的地质 过程. 这些淋滤的 $\mathrm{Ca}^{2+}$ 进入流体随后可能形成富钻矿 物，通过镜下观察在 $450^{\circ} \mathrm{C}$ 实验产物中发现了硬石膏 的形成(图15a), 在实际的斑岩矿床钾化带中也分布有 一些热液硬石膏(脉), 并可将其作为高氧逸度成矿流 体的标志(Yang等，2009; Cooke等，2014b; Chang等， 2018). 但也有研究将斑岩矿床致矿岩体中出现硬石膏 直接作为判断致矿岩浆具有高氧逸度的标志(Stern等, 2007; Liang等, 2009). 本次实验结果表明, 当斑岩体系 初始成矿流体中 $\mathrm{Ca}$ 含量不高时, 其中的硬石膏也可能 通过钾化过程中Ca淋滤和重新沉淀形成，因而其并不 一定能直接代表原生岩浆的氧化状态，因此在进行致 矿岩浆氧逸度判别时必须注意原生和次生硬石膏的 区分.

$450^{\circ} \mathrm{C}$ 和 $350^{\circ} \mathrm{C}$ 实验产物中 $\mathrm{MgO}$ 也发生明显的淋 滤，且较高温度条件下淋滤更强. 沿流体流向 $\mathrm{MgO}$ 的 淋滤逐渐变强, 而 $\mathrm{CaO}$ 的淋滤逐渐变弱. 其原因可能是 随着围岩中这两种元素的不断淋滤, 流体中 $\mathrm{Ca}^{2+}$ 和 $\mathrm{Mg}^{2+}$ 浓度逐渐升高，流体较高的 $\mathrm{Ca}^{2+}$ 浓度会减弱围岩 中 $\mathrm{Ca}$ 的淋滤，而流体 $\mathrm{Mg}^{2+}$ 浓度并不会影响围岩中 $\mathrm{Mg}$ 的淋滤，这可能与含 $\mathrm{Cl}^{-}$体系中 $\mathrm{Mg}^{2+}$ 具有较高的溶解 度有关(刘英俊, 1984). 在斑岩铜矿系统外围一般发育 有青磐岩化带, 其形成时间稍晚于钾化蚀变带, 该蚀变 带一般广泛分布富 $\mathrm{Mg}$ 矿物, 而且在偏基性的围岩中发 育更为广泛(Sillitoe, 2010). 本次实验结果很好的指示 了斑岩铜矿外围青磐岩化带可能的形成过程，从侵入 体出溶的高温流体在流经围岩尤其是偏基性岩石时, 会淋滤出围岩中的 $\mathrm{Mg} 、 \mathrm{Ca}$ 不断进入流体，这种富 $\mathrm{Ca} 、 \mathrm{Mg}$ 的流体在向外迁移过程中温度逐渐降低而使 其淋滤能力也逐渐减弱，进而在外围形成青磐岩化蚀 变带.

$450^{\circ} \mathrm{C}$ 和 $350^{\circ} \mathrm{C}$ 实验产物靠近流体中心 $\mathrm{SiO}_{2}$ 均发生

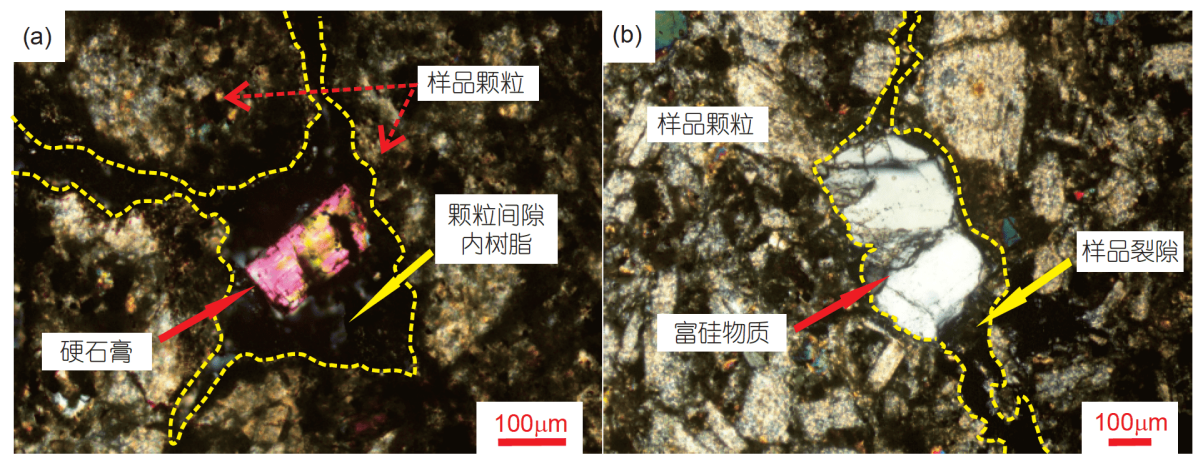

图 15 (网络版彩图) $450{ }^{\circ} \mathrm{C}$ 实验产物颗粒间隙硬石膏 $(\mathrm{a})$ 和 $350{ }^{\circ} \mathrm{C}$ 实验产物颗粒间隙硅质物(b) 颗粒间隙充填树脂 
明显的淋滤, 较高温条件下 $\mathrm{SiO}_{2}$ 淋滤更强. 随着远离流 体中心， $350^{\circ} \mathrm{C}$ 实验产物中 $\mathrm{SiO}_{2}$ 发生明显沉淀富集(图 $15 \mathrm{~b})$, 而 $450^{\circ} \mathrm{C}$ 实验产物中沉淀并不明显. 这表明温度 可能是控制流体内 $\mathrm{SiO}_{2}$ 溶解度的重要因素, 较高温度 条件下流体达到 $\mathrm{Si}$ 饱和所需 $\mathrm{Si}$ 含量更高, 所以高温条 件下围岩中 $\mathrm{SiO}_{2}$ 更易发生淋滤和迁移，较低温度下 $\mathrm{SiO}_{2}$ 淋滤较弱且不易发生迁移而是就近沉淀．前人实 验研究结果显示, 300 500 ${ }^{\circ} \mathrm{C}$ 和20 80MPa温压范围内, 石英在水中溶解度随温度升高有一个明显的下降趋势 (Fournier和Marshall, 1983; Fournier, 1999), 而本次 $450^{\circ} \mathrm{C}$ 实验产物中 $\mathrm{Si}$ 的淋滤和迁移更强, 这表明高温和 高盐度流体可能更容易淋滤和萃取硅酸盐矿物中的 $\mathrm{Si}$ ，成分复杂的硅酸盐具有和石英不同的 $\mathrm{Si}$ 溶解机理. 斑岩铜矿系统内靠近核部出溶的岩浆热液具有很高温 度, 因此其具有较强的溶解、迁移 $\mathrm{Si}$ 的能力并会导致 围岩中 Si含量降低，随着流体向外迁移其中 Si逐渐达 到饱和, 当温度进一步降低时在靠近核部外围发生沉 淀, 造成富含石英的脉体发育.

$450^{\circ} \mathrm{C}$ 实验产物中 $\mathrm{TiO}_{2}$ 含量的增加幅度明显高于 $350^{\circ} \mathrm{C}$ 实验产物，这表明 $\mathrm{Ti}^{4+}$ 在热液体系中的行为受温 度影响明显, 沿流体流向 $450^{\circ} \mathrm{C}$ 实验产物中 $\mathrm{Ti}$ 含量增加 有所减弱, 表明 $\mathrm{Ti}$ 的行为还受流体中 $\mathrm{Ti}^{4+}$ 浓度变化的影 响. 电子探针分析结果同样显示, $450^{\circ} \mathrm{C}$ 实验产物矿物 边部Ti含量增加也更明显(图8a和8b). 因此, Ti进入矿 物晶格中可能主要受温度和 $\mathrm{Ti}^{4+}$ 浓度的控制, 但 $450^{\circ} \mathrm{C}$ 实验产物中 Ti含量的增加远远高于 $350^{\circ} \mathrm{C}$ 实验产物, 因 此表明温度是控制 Ti进入矿物晶格最主要的控制因 素. $450^{\circ} \mathrm{C}$ 实验产物中 $\mathrm{Pb}$ 含量明显增加, $350^{\circ} \mathrm{C}$ 实验产物 中 $\mathrm{Pb}$ 含量不变, 而初始流体具有相近的 $\mathrm{Pb}^{2+}$ 浓度值, 表 明高温条件下 $\mathrm{Pb}^{2+}$ 更易进入矿物相中. 由于 $\mathrm{Pb}^{2+}$ 、 $\mathrm{Ba}^{2+} 、 \mathrm{~K}^{+}$离子半径相近, $\mathrm{Pb}^{2+}$ 可以与上述离子发生类 质同象(刘英俊，1984), 在本次实验体系中 $\mathrm{Pb}^{2+}$ 可能主 要是替换 $\mathrm{K}^{+}$进入长石. $450^{\circ} \mathrm{C}$ 实验产物中 $\mathrm{Pb}$ 含量更高 可能是较高温度下 $\mathrm{Pb}^{2+}$ 更易和矿物中的 $\mathrm{K}^{+}$发生置换, 但随流体流向 $\mathrm{Pb}$ 含量增加后又迅速下降，其机制需要 进一步的实验研究来确定. $\mathrm{Sr}$ 含量变化表明, $450^{\circ} \mathrm{C}$ 实 验产物中 $\mathrm{Sr}$ 含量增加, 而 $350^{\circ} \mathrm{C}$ 实验产物中 $\mathrm{Sr}$ 发生淋滤, 根据离子半径的大小 $\mathrm{Sr}^{2+}$ 主要置换钾长石中的 $\mathrm{K}^{+}$和斜 长石中的 $\mathrm{Ca}^{2+}$ (刘英俊, 1984), 本次实验结果表明此种 置换很可能只在大于 $350^{\circ} \mathrm{C}$ 的温度条件下发生, 而等于 或低于 $350^{\circ} \mathrm{C}$ 条件下这种置换较难发生, 围岩中 $\mathrm{Sr}$ 主要
发生淋滤.

\subsection{2 成矿元素矿化机制及外围矿化潜力}

实验产物均具有明显的 $\mathrm{Cu}$ 和 $\mathrm{S}$ 富集，表明初始流 体与岩石样品反应过程中发生了富 $\mathrm{Cu} 、 \mathrm{~S}$ 物质的沉淀, 通过镜下观察和电子探针分析结果显示, 生成的硫化 物类型主要有铜蓝(图16a), 还有大量的硫化物微粒因 粒径太小无法进行定量分析, 推测可能是黄铜矿或黄 铁矿(图16b). 产生硫化物的原因可能是反应过程中镍 合金材质的反应仓(合金以 $\mathrm{Ni}$ 为主含少量 $\mathrm{Cr} 、 \mathrm{Co}$ 和 $\mathrm{Fe}$ ) 提供了相对较低的氧逸度环境, 对应的氧逸度缓冲对 反应为 $2 \mathrm{Ni}+\mathrm{O}_{2}=2 \mathrm{NiO}$. 虽然我们无法精确的定量实验 体系的氧逸度值，但通过实验产物可以大致推断实验 体系的氧逸度范围. 实验产物中可以明显观察到原生 赤铁矿被部分还原成磁铁矿 (图16c 和16d), 而体系内 氧逸度不会低于NNO, 因此推测实验过程中反应釜内 氧逸度可能处在NNO-MH范围之间, 但Ni元素本身并 不会对体系的化学组成变化造成较大干扰. 体系氧逸 度降低使流体中硫酸根离子还原形成硫离子, 之后与 铜离子结合形成铜蓝和其他硫化物微粒. 电子探针分 析结果显示产物中部分镁铁质矿物边部 $\mathrm{Fe}$ 含量降低表 明发生了 $\mathrm{Fe}^{2+}$ 的淋滤, 这些淋滤出的 $\mathrm{Fe}^{2+}$ 可能与流体中 的 $\mathrm{S}^{2-}$ 和 $\mathrm{Cu}^{2+}$ 反应生成少量的黄铜矿和黄铁矿微粒. 虽 然斑岩铜矿钾化带中硬石膏和硫化物共生的现象表明 相对氧化的环境也可能导致硫化物的大量沉淀(Yang 等, 2009; Chang等, 2018), 但我们认为相比于高氧逸度 的原始岩浆出溶流体, 主成矿期流体可能仍需要经历 一个氧逸度下降过程, 其更有利于大量硫化物的沉淀, 而本次实验选用的镍合金材质反应仓可以提供这样一 个环境, 但为何我们实验产物中生成大量铜蓝而斑岩 铜矿中常见的黄铜矿和斑铜矿相对较少则需要进一步 研究.

$450^{\circ} \mathrm{C}$ 实验初始流体中 $\mathrm{Cu}$ 和 $\mathrm{S}$ 含量是 $350^{\circ} \mathrm{C}$ 实验初 始流体的 2 倍, 但 $450^{\circ} \mathrm{C}$ 实验产物中 $\mathrm{Cu}$ 和 $\mathrm{S}$ 沉淀量相对 于 $350^{\circ} \mathrm{C}$ 实验产物分别提高了近 10 倍和 20 倍，这与更 高温度条件下反应更强形成了更多的硫化物和硬石膏 有关. 远离流体中心, 实验产物中 $\mathrm{Cu} 、 \mathrm{~S}$ 含量明显降低 且高温条件下降低趋势更加显著, 其可能是硫化物沉 淀导致流体中铜和硫含量逐渐降低所致, 高温条件下 由于反应强烈导致这种降低趋势更加明显.

实验产物分析结果显示 $\mathrm{Zn} 、 \mathrm{Mn}$ 均发生淋滤，在 

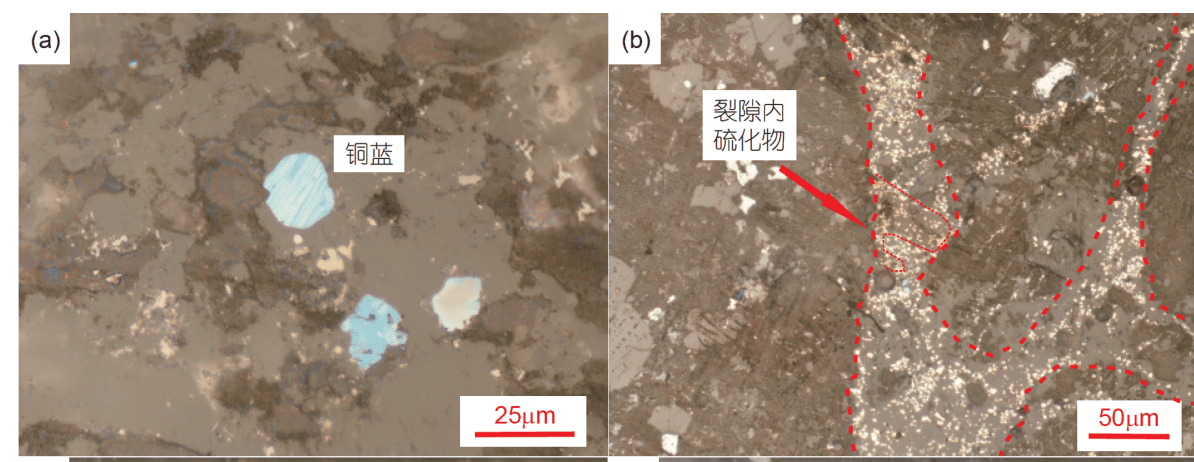

(c)

(d)
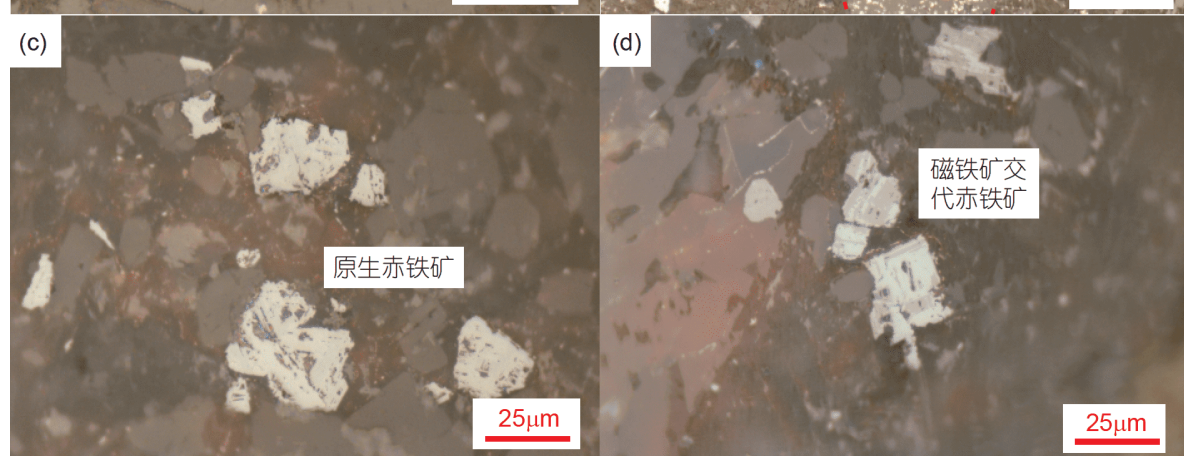

图 16 (网络版彩图)实验产物中形成的铜蓝(a)、硫化物微粒(b)、原始样品内赤铁矿(c)以及实验产物中磁铁矿交代赤铁矿 的现象(d)

$450^{\circ} \mathrm{C}$ 条件下淋滤更强, 因此其活化和迁移也可能主要 受温度的影响. $\mathrm{Zn}$ 是一种活动性较强的元素, 当热液 中含有碱金属和卤素时，岩石中的Zn可以产生一定的 活化和转移(刘英俊, 1984). 远离流体中心产物中 Mn 的淋滤程度逐渐减弱, 但高温实验产物中 Zn淋滤有变 强趋势, 这表明 $Z n$ 的淋滤还可能受其他因素的影响. 斑岩铜矿体系内热液在迁移过程中与围岩相互作用, 围岩中Zn由于发生淋滤也可能会进入流体(所占比例 可能很小), 这可能会对外围 $Z n$ 成矿具有积极作用. 实 验结果显示在高温热液中 $\mathrm{Zn}^{2+}$ 具有较强的迁移能力, 所以只有当流体搬运 $\mathrm{Zn}^{2+}$ 能力降低时才可能形成 $\mathrm{Zn}$ 矿 化. 例如当富 $\mathrm{Zn}^{2+}$ 流体迁移至外部遇到碳酸盐地层时, 流体降温导致搬运 $\mathrm{Zn}^{2+}$ 的能力下降并且含 $\mathrm{Zn}^{2+}$ 的络合 物被破坏，溶解度急剧降低导致 $Z n$ 的沉淀，在适宜的 空间聚集形成矿体(Sillitoe, 1973; Heinrich, 2006).

\section{4 特征元素迁移规律及其指示意义}

斑岩成矿系统中某些元素在空间上的分布规律, 可以为确定系统中心和寻找隐伏矿体提供良好的勘查 指标(Cooke等, 2017). 斑岩系统中成矿热液在向外迁 移过程中热量会逐渐耗散而发生降温，并且会持续与
火山围岩发生反应导致火山围岩组成发生连续变化. 火山围岩中特征组分的变化规律记录了成矿流体的流 动过程和途径, 以这些元素的变化规律为线索可以追 溯矿化中心. 根据不同温度实验产物中元素含量沿流 体流动方向的变化规律, 可以初步反演出斑岩系统围 岩中元素含量的空间分布特征，从而指示其在斑岩系 统中的相对位置. 本次实验选取玄武安山质火山岩作 为围岩介质, 因此实验结果所指示的元素变化规律和 指标主要适用于中-基性火山岩作为主要围岩介质的 斑岩铜矿系统.

$450^{\circ} \mathrm{C}$ 实验产物中 $\mathrm{K} 、 \mathrm{Ti}$ 含量明显高于 $350^{\circ} \mathrm{C}$ 实验 产物, 并且远离流体中心两者的含量均呈降低趋势, 表 明更高温度条件下热液中的 $\mathrm{K} 、 \mathrm{Ti}$ 更易进入固相，随 着流体向外迁移热液的温度和 $\mathrm{K} 、 \mathrm{Ti}$ 浓度逐渐降低, 导致围岩中 $\mathrm{K} 、 \mathrm{Ti}$ 含量的增加幅度逐渐变弱, 处在更 外部的围岩可能受低温流体的影响很微弱, 围岩中 $\mathrm{K} 、 \mathrm{Ti}$ 含量基本无变化. 因此可以推断距矿体较近的 高温蚀变带, 由于高温流体的交代作用使围岩中K、 $\mathrm{Ti}$ 含量较高, 随着流体向外迁移围岩中 $\mathrm{K} 、 \mathrm{Ti}$ 含量呈降 低趋势, 在更外围可能逐渐趋于背景值. $450^{\circ} \mathrm{C}$ 实验产 物在靠近流体中心 $\mathrm{Na}$ 发生淋滤, 沿流体流向 $\mathrm{Na}$ 逐渐富 
集, 而 $350^{\circ} \mathrm{C}$ 实验产物中 $\mathrm{Na}$ 含量整体呈增加趋势, 但两 者 $\mathrm{Na}$ 含量的增加幅度均很微弱. 该变化趋势表明, 靠 近斑岩系统核部的高温蚀变带围岩中 $\mathrm{Na}$ 主要发生淋 滤, 而随着逐渐远离高温中心围岩中 $\mathrm{Na}$ 逐步发生富集, 在高温蚀变带外围可能存在 $\mathrm{Na}$ 含量的过渡区. $450^{\circ} \mathrm{C}$ 和 $350^{\circ} \mathrm{C}$ 实验产物靠近流体中心 $\mathrm{SiO}_{2}$ 均发生明显淋滤, 远离流体中心 $450^{\circ} \mathrm{C}$ 实验产物中 $\mathrm{Si}$ 轻微富集而 $350^{\circ} \mathrm{C}$ 实 验产物中 $\mathrm{Si}$ 明显富集. 这表明靠近斑岩系统中心, 高温 流体的强烈淋滤导致围岩中 $\mathrm{Si}$ 亏损，流体向外迁移过 程中降温导致其淋滤能力降低并且 $\mathrm{Si}$ 逐渐达到饱和, 在高温蚀变带外围流体中饱和的 $\mathrm{Si}$ 发生沉淀和富集, 因此可能在靠近核部高温蚀变带外侧存在 $\mathrm{Si}$ 含量的峰 值区，该峰值区以广泛发育高石英含量的热液脉为特 征. 实验产物中 $\mathrm{Ca} 、 \mathrm{Zn}$ 和 $\mathrm{Mn}$ 均发生淋滤，且 $450^{\circ} \mathrm{C}$ 实 验产物淋滤程度明显强于 $350^{\circ} \mathrm{C}$ 实验产物，这表明温 度是导致以上三种元素淋滤的重要原因. 热液向外迁 移过程中逐渐降温导致围岩中 $\mathrm{Ca} 、 \mathrm{Zn}$ 和 $\mathrm{Mn}$ 的淋滤逐
渐减弱，因此火山围岩中三者的含量可能呈相对增加 趋势.

综上所述，斑岩铜矿体系中随离成矿中心(热液中 心)距离的增加，中-基性火山围岩中 $\mathrm{K} 、 \mathrm{Ti}$ 含量可能呈 降低趋势, $\mathrm{Ca} 、 \mathrm{Zn}$ 和 $\mathrm{Mn}$ 含量则可能呈升高趋势, 而 $\mathrm{Na}$ 和 $\mathrm{Si}$ 含量在高温蚀变带外围存在过渡区或峰值区(图 17). 以上推论是以单一来源的岩浆热液与中-基性火 山围岩反应为前提，但实际上后期矿化过程中还可能 会受到其他来源流体的叠加改造作用，因此围岩原有 的元素空间分布规律可能会发生改变，在运用上述元 素变化趋势进行矿化中心勘查指示时应谨慎.

\section{5 结论}

(1) 实验结果显示, $450^{\circ} \mathrm{C}$ 条件下体系内钾化蚀变 占据绝对主导, 而钠化蚀变微弱, 随温度降低钾化逐渐 减弱而钠化相对变强. 高温条件下 $\mathrm{K}^{+}$对 $\mathrm{Na}^{+}$行为的抑

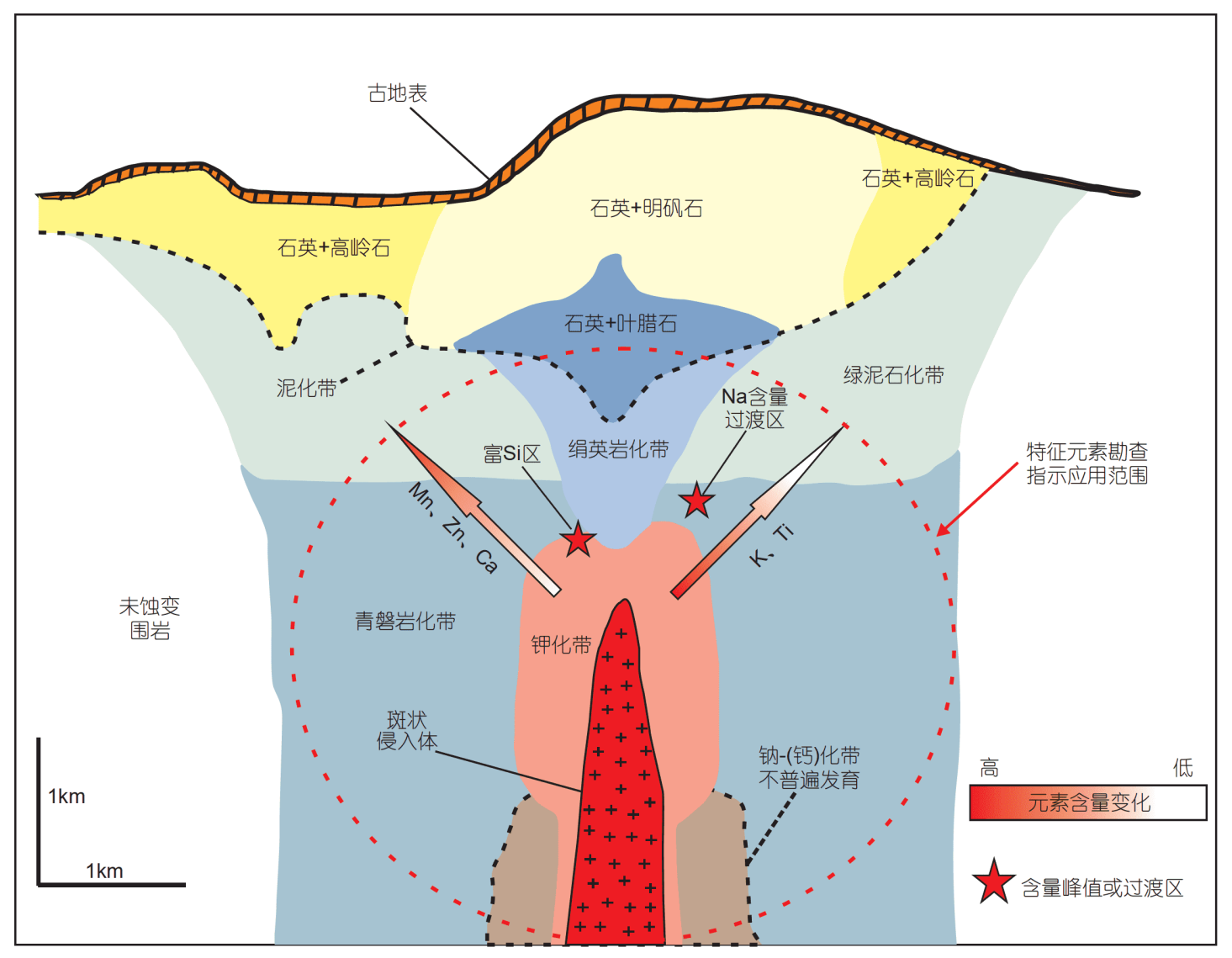

图 17 (网络版彩图)斑岩成矿系统中-基性火山围岩内特征元素含量变化趋势及空间分布范围 底图修改自Sillitoe(2010) 
制作用，可能是导致斑岩成矿系统核部普遍发育钾化 带而缺失钠化带的重要原因.

(2) 斑岩体系高温流体交代围岩导致 $\mathrm{Ca}$ 活化, 可提 高流体中 $\mathrm{Ca}$ 含量和形成热液硬石膏. 高温水-岩反应也 可能为成矿流体提供部分的 $\mathrm{Mg} 、 \mathrm{Zn} 、 \mathrm{Mn}$ 等元素，这 与形成外围青磐岩化密切相关，高温流体也是控制 $\mathrm{Ti} 、 \mathrm{~Pb} 、 \mathrm{Sr}$ 进入硅酸盐矿物发生元素置换的重要 因素.

(3) 实验结果表明，斑岩成矿系统内含矿热液与 中-基性火山围岩反应，导致围岩内元素发生活化和迁 移, 其中 $+1 、+2$ 价金属元素较易淋滤, 而 $\mathrm{Al} 、 \mathrm{Si}$ 较难发 生淋滤. 通过实验结果可以初步推断, 斑岩成矿系统由 中心向外围，中-基性火山围岩中K和 $\mathrm{Ti}$ 含量可能呈降 低趋势, $\mathrm{Ca} 、 \mathrm{Zn}$ 和 $\mathrm{Mn}$ 含量逐渐增加, $\mathrm{Si}$ 和 $\mathrm{Na}$ 含量在靠 近高温蚀变区外围可能存在峰值或过渡区域.

致谢在实验操作及产物处理、分析测试过程中得到了 中国科学院地质与地球物理研究所兰州油气资源研究中 心张东伟, 中山大学李登峰博士, 中国科学院广州地球化 学研究所张世涛、赵联党、许超和黄健瀚博士的帮助, 三 位审稿专家提出了诸多宝贵修改意见, 在此一致表示感谢.

\section{参考文献}

陈华勇, 肖兵. 2014. 俯冲边界成矿作用研究进展及若干问题. 地学 前缘, 21: 13-22

党志, 侯㻤. 1995. 玄武岩-水相互作用的溶解机理研究. 岩石学报, 11: 9-15

杜乐天. 1986. 碱交代作用地球化学原理. 中国科学, 1: 83-92

杜建国. 2010. 高压地球科学. 北京: 地震出版社

胡书敏, 张荣华, 张雪肜, 苏艳丰. 2010. 庐枞火山盆地玄武岩与流体 相互作用. 岩石学报, 26: 2681-2693

刘玉山, 张桂兰. 1996. $250 \sim 500^{\circ} \mathrm{C}, 100 \mathrm{MPa}$ 下海水-玄武岩反应的实 验研究. 地球化学, 1: 53-62

刘英俊. 1984. 元素地球化学. 北京: 科学出版社. 304

刘颖, 刘海臣, 李献华. 1996. 用ICP-MS准确测定岩石样品中的 40 余 种微量元素. 地球化学, 6: 552-558

黄文斌, 张荣华, 胡书敏. 2011. 临界态附近玄武岩-海水相互作用化 学动力学. 矿物学报. 629

孙卫东, 凌明星, 杨晓勇, 范蔚苔, 丁兴, 梁华英. 2010. 洋脊俯冲与斑 岩铜金矿成矿. 中国科学: 地球科学, 40: 127-137

谭凯旋, 张哲儒, 王中刚. 1994. 矿物溶解的表面化学动力学机理. 矿 物学报, 3: 207-214
王云峰, 陈华勇, 肖兵, 韩金生. 2016. 新疆东天山地区土屋和延东铜 矿床斑岩-叠加改造成矿作用. 矿床地质, 35: 51-68

王玉荣, 王志祥, 张生. 2000. 水/岩反应实验与成矿作用. 矿物岩石地 球化学通报, 19: 426-427

张德会, 徐九华, 余心起, 李健康, 毛世德, 王科强, 李泳泉. 2011. 成 岩成矿深度: 主要影响因素与压力估算方法. 地质通报, 30: 112125

张有学. 2010. 地球化学动力学. 北京: 高等教育出版社

Aagaard P, Helgeson H C. 1982. Thermodynamic and kinetic constraints on reaction rates among minerals and aqueous solutions: I, Theoretical considerations. Am J Sci, 282: 237-285

Ague J J, Brimhall G H. 1989. Geochemical modeling of steady state fluid flow and chemical reaction during supergene enrichment of porphyry copper deposits. Econ Geol, 84: 506-528

Airy G B. 1855. On the computation of the effect of the attraction of mountain-masses, as disturbing the apparent astronomical latitude of stations in geodetic surveys. Philos Trans R Soc Lond, 145: 101104

Barnes H L. 1997. Geochemistry of Hydrothermal Ore Deposits. 3rd ed. John Wiley \& Sons. 1

Bickle M, Baker J. 1990. Migration of reaction and isotopic fronts in infiltration zones: Assessments of fluid flux in metamorphic terrains. Earth Planet Sci Lett, 98: 1-13

Bird D K, Schiffman P, Elders W A, Williams A E, McDowell S D. 1984. Calc-silicate mineralization in active geothermal systems. Econ Geol, 79: 671-695

Bondar R J, Sanchez P L, Moncada D, Macinnis M S. 2014. Fluid inclusions in hydrothermal ore deposits. Treat Geochem, 13: 119142

Brimhall G H. 1977. Early fracture-controlled disseminated mineralization at Butte, Montana. Econ Geol, 72: 37-59

Carmichael D M. 1987. Induced stress and secondary mass transfer: Thermodynamic basis for the tendency toward constant-volume constraint in diffusion metasomatism. In: Helgeson $\mathrm{H}$ C, ed. Chemical Transport in Metasomatic Processes. NATO ASI Series (Series C: Mathematical and Physical Sciences). Dordrecht: Springer

Carten R B. 1986. Sodium-calcium metasomatism; chemical, temporal, and spatial relationships at the Yerington, Nevada, porphyry copper deposit. Econ Geol, 81: 1495-1519

Chang J, Li J W, Audétat A. 2018. Formation and evolution of multistage magmatic-hydrothermal fluids at the Yulong porphyry $\mathrm{Cu}-\mathrm{Mo}$ deposit, eastern Tibet: Insights from LA-ICP-MS analysis of fluid inclusions. Geochim Cosmochim Acta, 232: 181-205

Cooke D R, Hollings P, Walshe J L. 2005. Giant porphyry deposits: Characteristics, distribution, and tectonic controls. Econ Geol, 100: 
$801-818$

Cooke D R, Baker M, Hollings P, Sweet G, Chang Z, Danyushevsky L, Gilbert G, Zhou T, White N C, Gemmell J B, Inglis S. 2014a. New advances in detecting systems-epidote mineral chemistry as a tool for vectoring and fertility assessments. Soc Econ Geol Spec Publ, 18: $127-152$

Cooke D R, Hollings P, Wilkinson J J, Tosdal R M. 2014b. Geochemistry of porphyry deposits. Treat Geochem, 13: 357-381

Ferry J M, Dipple G M. 1991. Fluid flow, mineral reactions, and metasomatism. Geology, 19: 211-214

Ferry J M, Dipple G M. 1992. Models for coupled fluid flow, mineral reaction, and isotopic alteration during contact metamorphism: The Notch Peak aureole, Utah. Am Miner, 77: 577-591

Fournier R O. 1999. Hydrothermal processes related to movement of fluid from plastic into brittle rock in the magmatic-epithermal environment. Econ Geol, 94: 1193-1211

Fournier R O, Marshall W L. 1983. Calculation of amorphous silica solubilities at 25 to $300^{\circ} \mathrm{C}$ and apparent cation hydration numbers in aqueous salt solutions using the concept of effective density of water. Geochim Cosmochim Acta, 47: 587-596

Frank M R, Candela P A, Piccoli P M. 1998. K-feldspar-muscoviteandalusite-quartz-brine phase equilibria: An experimental study at 25 to $60 \mathrm{MPa}$ and 400 to $550^{\circ} \mathrm{C}$. Geochim Cosmochim Acta, 62 $3717-3727$

Frank M R, Vaccaro D M. 2012. An experimental study of high temperature potassic alteration. Geochim Cosmochim Acta, 83: 195-204

Gautier J M, Oelkers E H, Schott J. 1994. Experimental study of Kfeldspar dissolution rates as a function of chemical affinity at $150^{\circ} \mathrm{C}$ and $\mathrm{pH}$ 9. Geochim Cosmochim Acta, 58: 4549-4560

Gislason S R, Oelkers E H. 2003. Mechanism, rates, and consequences of basaltic glass dissolution: II. An experimental study of the dissolution rates of basaltic glass as a function of $\mathrm{pH}$ and temperature. Geochim Cosmochim Acta, 67: 3817-3832

Gudbrandsson S, Wolff-Boenisch D, Gislason S R, Oelkers E H. 2011. An experimental study of crystalline basalt dissolution from $2 \leq \mathrm{pH} \leq 11$ and temperatures from 5 to $75^{\circ} \mathrm{C}$. Geochim Cosmochim Acta, 75: 5496-5509

Harris N B W, Inger S, Ronghua X. 1990. Cretaceous plutonism in Central Tibet: An example of post-collision magmatism? J Volcanol Geotherm Res, 44: 21-32

Halter W E, Pettke T, Heinrich C A. 2002. The origin of $\mathrm{Cu} / \mathrm{Au}$ ratios in porphyry-type ore deposits. Science, 296: 1844-1846

Haselton Jr. H T, Cygan G L, Jenkins D M. 1995. Experimental study of muscovite stability in pure $\mathrm{H}_{2} \mathrm{O}$ and 1 molal $\mathrm{KCl}-\mathrm{HCl}$ solutions. Geochim Cosmochim Acta, 59: 429-442
Hutcheon I, Shevalier M, Abercrombie H J. 1993. pH buffering by metastable mineral-fluid equilibria and evolution of carbon dioxide fugacity during burial diagenesis. Geochim Cosmochim Acta, 57: $1017-1027$

Helgeson H C. 1969. Thermodynamics of hydrothermal systems at elevated temperatures and pressures. Am J Sci, 267: 729-804

Heinrich C A. 1990. The chemistry of hydrothermal tin(-tungsten) ore deposition. Econ Geol, 85: 457-481

Heinrich C A. 2005. The physical and chemical evolution of lowsalinity magmatic fluids at the porphyry to epithermal transition: A thermodynamic study. Miner Deposita, 39: 864-889

Heinrich C A. 2006. From fluid inclusion microanalysis to large-scale hydrothermal mass transfer in the Earth's interior. J Mineral Petrol Sci, 101: 110-117

Heinrich C A, Walshe J L, Harrold B P. 1996. Chemical mass transfer modelling of ore-forming hydrothermal systems: Current practise and problems. Ore Geol Rev, 10: 319-338

Hemley J J. 1959. Some mineralogical equilibria in the system $\mathrm{K}_{2} \mathrm{O}-$ $\mathrm{Al}_{2} \mathrm{O}_{3}-\mathrm{SiO}_{2}-\mathrm{H}_{2} \mathrm{O}$. Am J Sci, 257: 241-270

Hemley J J, Jones W R. 1964. Chemical aspects of hydrothermal alteration with emphasis on hydrogen metasomatism. Econ Geol, 59: $538-569$

Hemley J J, Montoya J W, Marinenko J W, Luce R W. 1980. Equilibria in the system $\mathrm{Al}_{2} \mathrm{O}_{3}-\mathrm{SiO}_{2}-\mathrm{H}_{2} \mathrm{O}$ and some general implications for alteration/mineralization processes. Econ Geol, 75: 210-228

Hildreth W, Moorbath S. 1988. Crustal contributions to arc magmatism in the Andes of central Chile. Contr Mineral Petrol, 98: 455-489

Holyland P W. 1987. Dynamic modelling at the Renison tin mine. Pacific Rim Congress. 87. 189-193

Kerrich R. 2000. The geodynamics of world-class gold deposits, characteristics, space-time distribution, and origins. Rev Econ Geol, 13: $501-551$

Korzhinskii D S. 1959. Acid-basic interaction of components in silicate melts and the direction of the cotectic lines. Doklady Akademii Nauk SSSR, 128: 383-386

Korzhiniskii D S. 1970. Theory of Metasomatie Zoning. Oxford: Oxford University Press

Landtwing M R, Pettke T, Halter W E, Heinrich C A, Redmond P B, Einaudi M T, Kunze K. 2005. Copper deposition during quartz dissolution by cooling magmatic-hydrothermal fluids: The Bingham porphyry. Earth Planet Sci Lett, 235: 229-243

Landtwing M R, Furrer C, Redmond P B, Pettke T, Guillong M, Heinrich C A. 2010. The Bingham Canyon porphyry Cu-Mo-Au deposit. III. Zoned copper-gold ore deposition by magmatic vapor expansion. Econ Geol, 105: 91-118

Liang H Y, Sun W, Su W C, Zartman R E. 2009. Porphyry copper-gold 
mineralization at Yulong, China, promoted by decreasing redox potential during magnetite alteration. Econ Geol, 104: 587-596

Lasaga A C, Rye D M. 1993. Fluid flow and chemical reaction kinetics in metamorphic systems. Am J Sci, 293: 361-404

Lowell J D, Guilbert J M. 1970. Lateral and vertical alterationmineralization zoning in porphyry ore deposits. Econ Geol, 65: 373408

Luhmann A J, Tutolo B M, Tan C, Moskowitz B M, Saar M O, Seyfried $\mathrm{Jr}$ W E. 2017. Whole rock basalt alteration from $\mathrm{CO}_{2}$-rich brine during flow-through experiments at $150^{\circ} \mathrm{C}$ and 150 bar. Chem Geol, 453: $92-110$

Merino E, Moore C, Ortoleva P, Ripley E. 1986. Mineral zoning in sediment-hosted copper-iron sulfide deposits-A quantitative kinetic approach. In: Geology and Metallogeny of Copper Deposits. Special Publication No. 4 of the Society for Geology Applied to Mineral Deposits. Berlin: Springer. 559-571

Montoya J W, Hemley J J. 1975. Activity relations and stabilities in alkali feldspar and mica alteration reactions. Econ Geol, 70: 577583

Mottl M J, Holland H D. 1978. Chemical exchange during hydrothermal alteration of basalt by seawater-I. Experimental results for major and minor components of seawater. Geochim Cosmochim Acta, 42: 1103-1115

Murphy W M, Oelkers E H, Lichtner P C. 1989. Surface reaction versus diffusion control of mineral dissolution and growth rates in geochemical processes. Chem Geol, 78: 357-380

Nash J T. 1976. Fluid-inclusion petrology—Data from porphyry copper deposits and applications to exploration: A summary of new and published descriptions of fluid inclusions from 36 porphyry copper deposits and discussion of possible applications to exploration for copper deposits. US Govt. Print. Off

Oelkers E H. 2001. General kinetic description of multioxide silicate mineral and glass dissolution. Geochim Cosmochim Acta, 65: 3703-3719

Oelkers E H, Schott J. 2001. An experimental study of enstatite dissolution rates as a function of $\mathrm{pH}$, temperature, and aqueous $\mathrm{Mg}$ and $\mathrm{Si}$ concentration, and the mechanism of pyroxene/pyroxenoid dissolution. Geochim Cosmochim Acta, 65: 1219-1231

Oelkers E H, Schott J, Devidal J L. 1994. The effect of aluminum, pH, and chemical affinity on the rates of aluminosilicate dissolution reactions. Geochim Cosmochim Acta, 58: 2011-2024

Orville P M. 1962. Alkali metasomatism and feldspars. Norsk Geologisk Tidsskrift. 283-316

Pollard P J. 2001. Sodic(-calcic) alteration in Fe-oxide-Cu-Au districts: An origin via unmixing of magmatic $\mathrm{H}_{2} \mathrm{O}-\mathrm{CO}_{2}-\mathrm{NaCl} \pm \mathrm{CaCl}_{2}-\mathrm{KCl}$ fluids. Mineralium Deposita, 36: 93-100
Ré C L, Kaszuba J P, Moore J N, McPherson B J. 2014. Fluid-rock interactions in $\mathrm{CO}_{2}$-saturated, granite-hosted geothermal systems: Implications for natural and engineered systems from geochemical experiments and models. Geochim Cosmochim Acta, 141: 160-178

Redmond P B, Einaudi M T, Inan E E, Landtwing M R, Heinrich C A. 2004. Copper deposition by fluid cooling in intrusion-centered systems: New insights from the Bingham porphyry ore deposit, Utah. Geology, 32: 217-220

Redmond P B, Einaudi M T. 2010. The Bingham Canyon porphyry Cu$\mathrm{Mo}-\mathrm{Au}$ deposit. I. Sequence of intrusions, vein formation, and sulfide deposition. Econ Geol, 105: 43-68

Reed M H. 1997. Hydrothermal alteration and its relationship to ore fluid composition. Geochem Hydrothermal Ore Deposits, 1: 303365

Richards J P. 2011. Magmatic to hydrothermal metal fluxes in convergent and collided margins. Ore Geol Rev, 40: 1-26

Richards J P, Kerrich R. 2007. Special paper: Adakite-like rocks: Their diverse origins and questionable role in metallogenesis. Econ Geol, 102: $537-576$

Ringwood A E. 1977. Petrogenesis in island arc systems. Island arcs, deep sea trenches and back-arc basins. Washington: American Geophysical Union. 311-324

Roedder E. 1971. Fluid inclusion studies on the porphyry-type ore deposits at Bingham, Utah, Butte, Montana, and Climax, Colorado. Econ Geol, 66: 98-118

Rogers K L, Neuhoff P S, Pedersen A K, Bird D K. 2006. $\mathrm{CO}_{2}$ metasomatism in a basalt-hosted petroleum reservoir, Nuussuaq, West Greenland. Lithos, 92: 55-82

Rusk B G, Reed M H, Dilles J H, Klemm L M, Heinrich C A. 2004. Compositions of magmatic hydrothermal fluids determined by LAICP-MS of fluid inclusions from the porphyry copper-molybdenum deposit at Butte, MT. Chem Geol, 210: 173-199

Rusk B G, Reed M H, Dilles J H. 2008. Fluid inclusion evidence for magmatic-hydrothermal fluid evolution in the porphyry coppermolybdenum deposit at Butte, Montana. Econ Geol, 103: 307-334

Schott J, Pokrovsky O S, Oelkers E H. 2009. The link between mineral dissolution/precipitation kinetics and solution chemistry. Rev Mineral Geochem, 70: 207-258

Seedorff E, Barton M D, Stavast W J A, Maher D J. 2008. Root zones of porphyry systems: Extending the porphyry model to depth. Econ Geol, 103: 939-956

Seedorff E, Dilles J H, Proffett J M. 2005. Porphyry deposits: Characteristics and origin of hypogene features. Econ Geol, 100: 251-298

Sillitoe R H. 1972. A plate tectonic model for the origin of porphyry copper deposits. Econ Geol, 67: 184-197 
Sillitoe R H. 1973. The tops and bottoms of porphyry copper deposits. Econ Geol, 68: 799-815

Sillitoe R H. 2010. Porphyry copper systems. Econ Geol, 105: 3-41

Stern C R, Funk J A, Skewes M A, Arevalo A. 2007. Magmatic anhydrite in plutonic rocks at the El Teniente $\mathrm{Cu}-\mathrm{Mo}$ deposit chile, and the role of sulfur- and copperrich magmas in its formation. Econ Geol, 102: 1335-1344

Sun S, McDonough W F. 1989. Chemical and isotopic systematics of oceanic basalts: Implications for mantle composition and processes. Geol Soc Lond Spec Publ, 42: 313-345

Sverjensky D A, Hemley J J, D'angelo W M. 1991. Thermodynamic assessment of hydrothermal alkali feldspar-mica-aluminosilicate equilibria. Geochim Cosmochim Acta, 55: 989-1004
Wilkinson J J, Chang Z, Cooke D R, Baker M J, Wilkinson C C, Inglis S, Chen H, Bruce Gemmell J. 2015. The chlorite proximitor: A new tool for detecting porphyry ore deposits. J Geochem Exploration, 152: $10-26$

Winkler H G F, von Platen H. 1961. Experimentelle Gesteinsmetamorphose-V. Geochim Cosmochim Acta, 24: 250-259

Xiao B, Chen H Y, Hollings P, Han J S, Wang Y F, Yang J T, Cai K D. 2015. Magmatic evolution of the Tuwu-Yandong porphyry $\mathrm{Cu}$ belt, NW China: Constraints from geochronology, geochemistry and SrNd-Hf isotopes. Gondwana Res, 43: 74-91

Yang Z, Hou Z, White N C, Chang Z S, Li Z Q, Song Y C. 2009. Geology of the post-collisional porphyry copper-molybdenum deposit at Qulong, Tibet. Ore Geol Rev, 36: 133-159

(责任编委: 倪怀玮) 